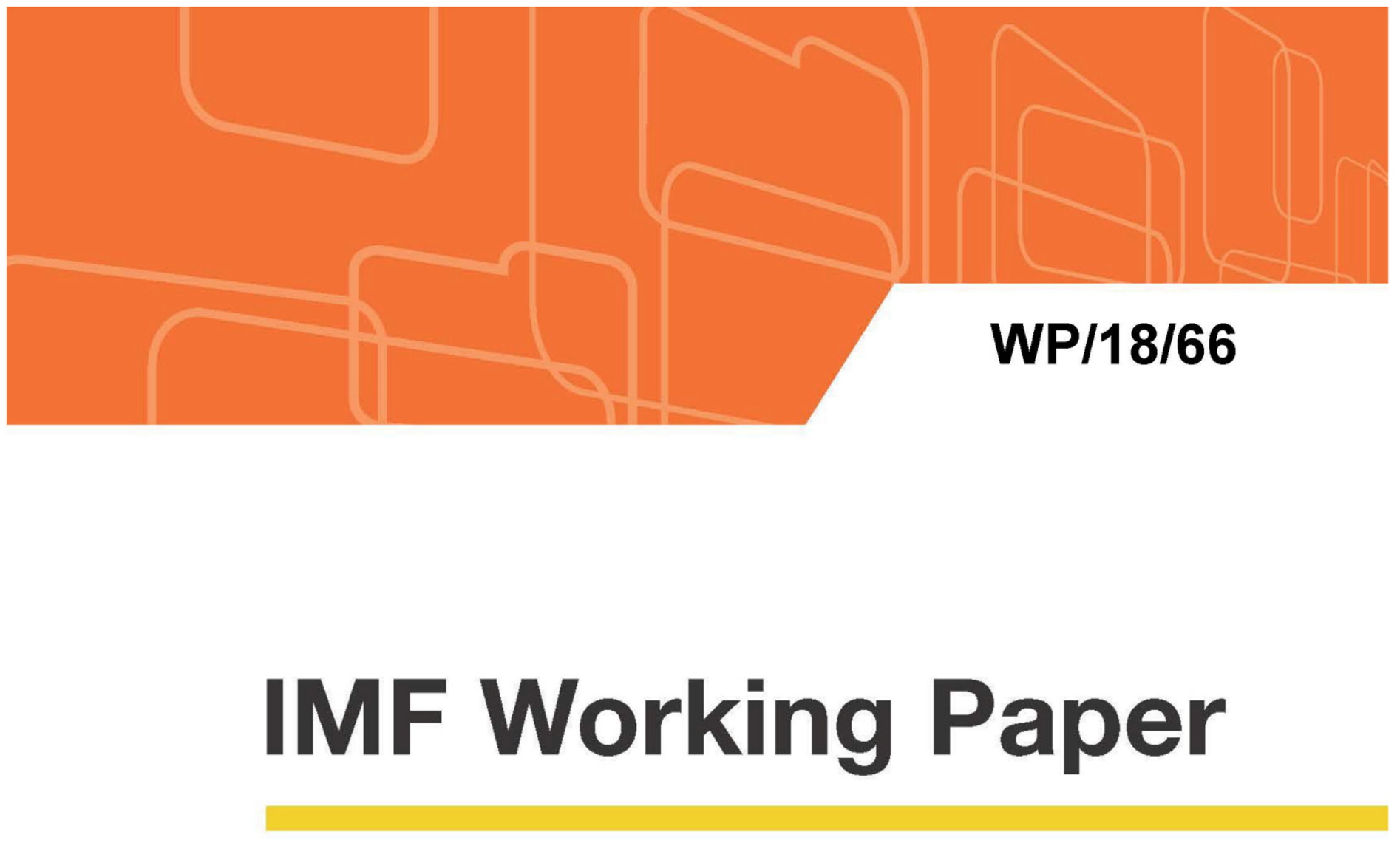

\title{
Organizing Central Securities Depositories in Developing Markets-7 Considerations
}

by Froukelien Wendt, Peter Katz, and Alice Zanza

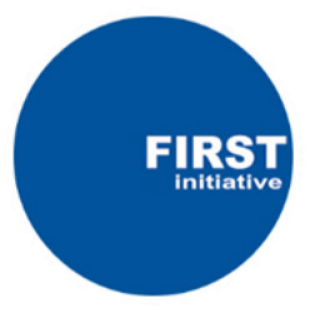

IMF Working Papers describe research in progress by the author(s) and are published to elicit comments and to encourage debate. The views expressed in IMF Working Papers are those of the author(s) and do not necessarily represent the views of the IMF, its Executive Board, or IMF management. 


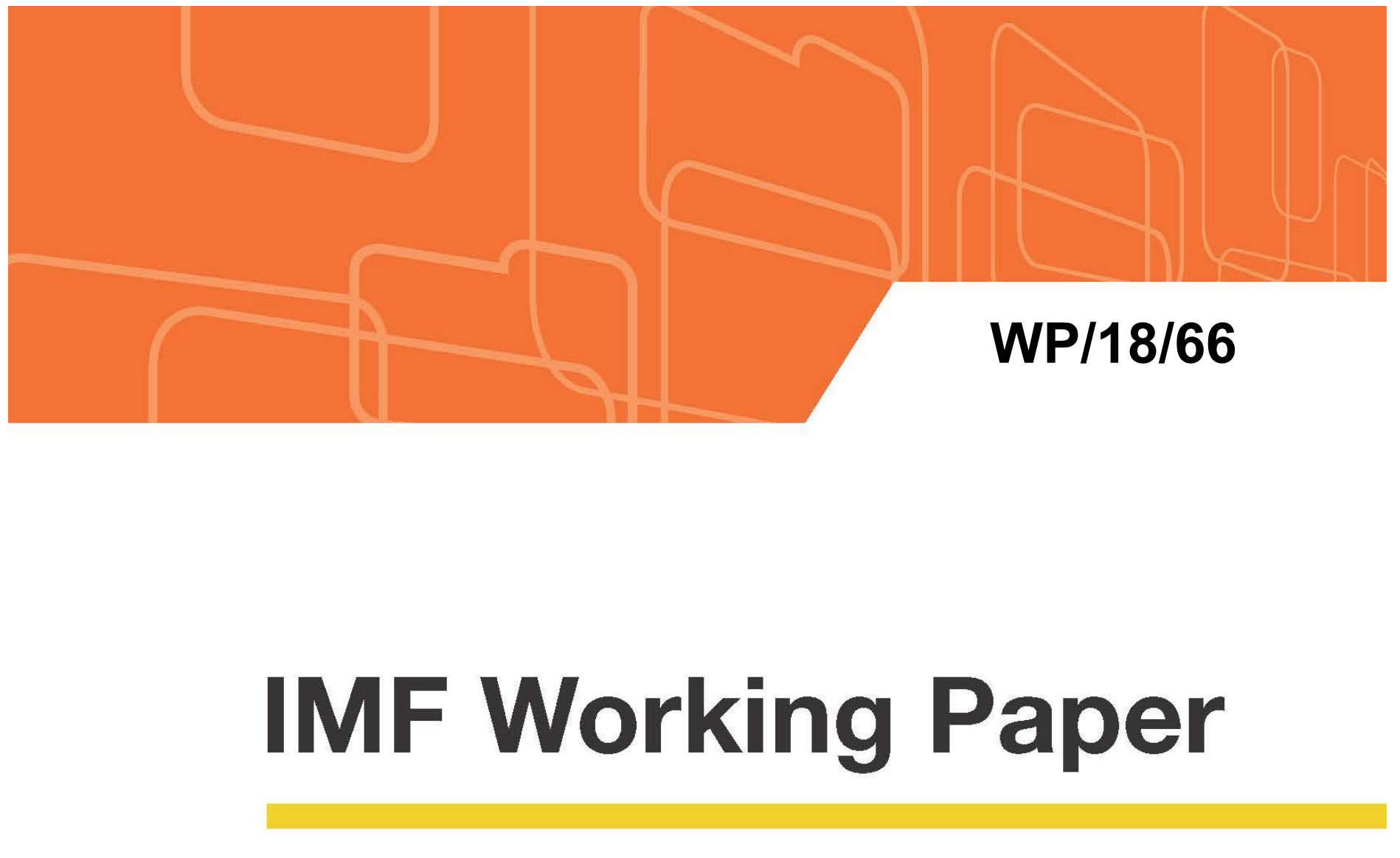

\title{
Organizing Central Securities Depositories in Developing Markets-7 Considerations
}

\author{
by Froukelien Wendt, Peter Katz, and Alice Zanza
}

IMF Working Papers describe research in progress by the author(s) and are published to elicit comments and to encourage debate. The views expressed in IMF Working Papers are those of the author(s) and do not necessarily represent the views of the IMF, its Executive Board, or IMF management.

$$
\text { I N T E R N A T I O N A L M O N E T A R Y F U N D }
$$




\title{
IMF Working Paper
}

Monetary and Capital Markets Department

\section{Organizing Central Securities Depositories in Developing Markets—7 Considerations \\ Prepared by Froukelien Wendt, Peter Katz, and Alice Zanza}

Authorized for distribution by Ghiath Shabsigh

March 2018

\section{IMF Working Papers describe research in progress by the author(s) and are published to} elicit comments and to encourage debate. The views expressed in IMF Working Papers are those of the author(s) and do not necessarily represent the views of the IMF, its Executive Board, or IMF management.

\begin{abstract}
Central securities depositories (CSDs) are systemically important entities that are critical for effective implementation of monetary policy, the credibility of a government's debt management program, collateral management, and safe and efficient securities markets. Authorities in developing markets, in particular central banks, may grapple with the following issues: i) whether to pursue a single CSD for all types of securities to increase market efficiencies and benefit from economies of scale; and ii) whether to partake in the governance of the CSD as owner and/or operator. This paper develops seven considerations that authorities may take into account in addressing these issues and finding the best model for their country. These may point to different solutions for different countries, depending in part on the size of markets, strength of private operators and level of market development.
\end{abstract}

JEL Classification Numbers: G01, G18, G23, G28

Keywords: Central securities depositories, financial market development, securities, clearing

Author's E-Mail Addresses: : fwendt@,imf.org, peterkatz.consulting@googlemail.com, azanza@worldbank.org.

The authors are grateful for the input from the central banks and other supervisory authorities from India, Kyrgyz Republic, Lithuania, Mexico, Philippines, Rwanda, and Tanzania, and comments from Fady Alrayyes, Noritaka Akamatsu, Roberto José Campo, José Antonia, Garcia, Maimouna Gueye, Vacharakoon Jivakanont, Elias Kazarian, Tanai Khiaonarong, Raúl Morales Reséndiz, and Wilson Varghese. Research assistance was provided by Shaoyu Guo. All remaining errors are the authors' responsibility. 


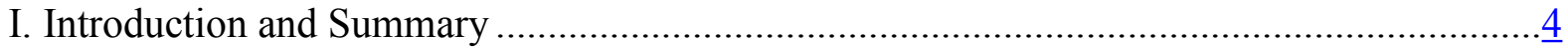

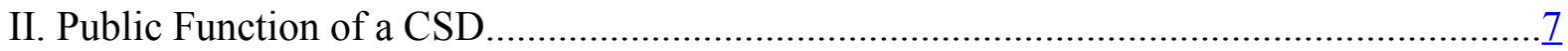

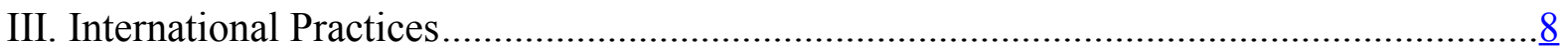

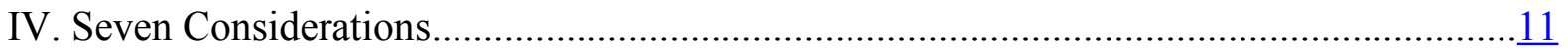

A. Single or Multiple CSDs ............................................................................. 12

B. Public or Private Operator .......................................................................... $\frac{19}{23}$

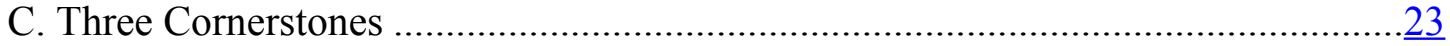

V. Outcomes of Decision Making — 4 models ................................................................ 26

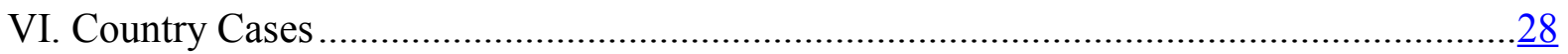

A. India: efficiencies through competition in the stock market ............................. 28

B. Kyrgyz Republic: two CSDs for stability reasons ............................................29

C. Lithuania: gradual sale of public stake in CSD .................................................

D. Mexico: a single CSD operated by a private entity .........................................

E. Philippines: Ministry of Finance involved in governance of CSD ....................... $\underline{32}$

F. Rwanda: a single CSD operated by the central bank .....................................

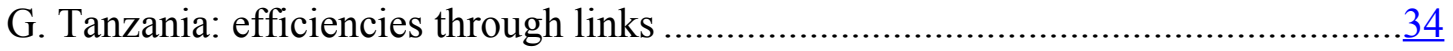

Figures

1. Regional differences in the organization of CSDs........................................................

2. Types of Securities settled by Central Banks and Non-Central Bank Operators ................10

3. CSD Governance per income level.......................................................................... 10

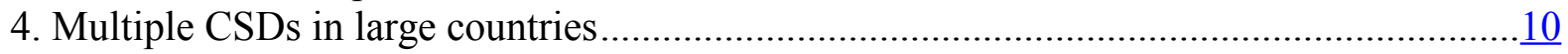

5. Considerations and cornerstones for the organization of CSDs .................................11

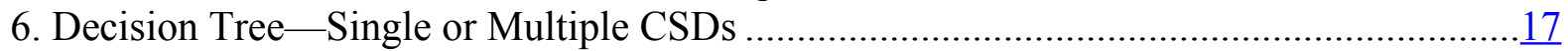

7. Decision Tree-Private or Public Ownership and Operations ...................................... 23

Boxes

1. CSD Services .................................................................................................. 5

2. Seven Considerations for The Organization of CSD Functions in Developing Markets ....... $\underline{6}$

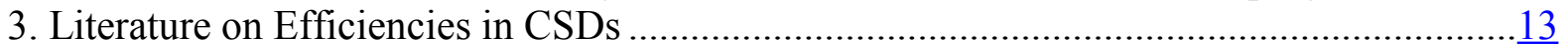

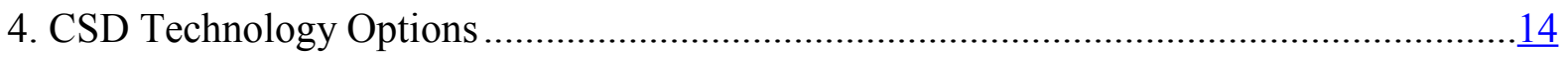

5. Efficiencies through cross border integration ..................................................... 17

Annexes

1. Global Map of Central Securities Depositories ......................................................... $\underline{38}$

2. Decision Tree Combining Safety and Efficiency Considerations ................................... $\underline{39}$ 


\section{INTRODUCTION AND SUMMARY}

The key objective of this paper is to support authorities in their decision-making about the optimal organization of central securities depositories (CSDs) in their country. For the purpose of this paper a CSD is defined as an entity that provides securities accounts, a securities settlement system and central safekeeping services to market participants, which can be banks and other financial institutions. ${ }^{1}$ These services are further described in Box 1.

In their interactions with countries worldwide the IMF and World Bank have noted that authorities in developing markets, in particular central banks, may grapple with two questions: i) whether to pursue a single CSD to increase market efficiencies and benefit from economies of scale and scope; and ii) whether to partake in the governance of the CSD as owner and/or operator.

This paper presents seven considerations that authorities may take into account in answering these questions and determining the best model for their country (Box 2). There is no evident international best practice on how to organize CSDs at a national level. Rather, the paper argues that the optimal model depends on the country's specific circumstances and features, such as the size of its markets, strength of private operators and the level of market development. The seven considerations are supplemented by decision trees, which are intended to guide authorities in finding the model that best fits their country. Based on the guidance different countries may come to different conclusions. The outcome for country A may be to pursue a single CSD operated by the central bank, whereas the outcome for country B would be to pursue a single CSD operated by a private operator. Similarly, multiple CSDs could be the optimal solution for other countries.

The main recommendation is that authorities should strike the right balance between safety and efficiency considerations for securities markets. Although a single CSD can be the most efficient solution from a cost-perspective, this option should only be pursued if there is a strong indication that the safety and soundness of the securities market are not at stake. In the same vein, although central banks may consider that owning and operating a CSD is not in their core mandate, a CSD can only be owned and operated by private entities if these entities have the capacity to address public interests. Otherwise, the central bank may be best placed to own and operate the CSD. Furthermore, three cornerstones underpin any decision about (re)organizing CSD functions, which are a sound legal framework, effective supervision and oversight, and cooperation and coordination amongst all stakeholders, both private and public.

\footnotetext{
${ }^{1}$ A securities settlement system may operate independently from a CSD, however, in developing markets CSDs typically operate a securities settlement system. That is why this report defines CSDs as operator of a securities settlement system, among others. Some CSDs in developed markets may have additional functions, such as credit provision (often under a banking license) or accepting cash deposits. These functions are typically not a feature of CSDs in developed markets and therefore not included in the definition.
} 


\section{Box 1. CSD Services}

A CSD may be a fully-fledged automated system, but may also be a manually operated register of securities accounts. Services of a CSD typically include the provision of:

a. Securities accounts: Issuers of securities may deposit their securities into a CSD, allowing investors to hold and trade these securities in a centralized system. In many countries, the CSD provides securities accounts to banks and other professional entities that hold the securities on behalf of investors. In some countries, investors may open an account in the CSD directly, without intermediation of banks or other financial entities.

b. A securities settlement system: A securities settlement system enables securities to be transferred and settled on securities accounts according to a set of predetermined multilateral rules. The trend in developing markets is towards automated book entry processing of dematerialized or immobilized securities, however, in some countries the debiting and crediting of securities accounts takes place manually and securities are still in physical form. The settlement of securities often involves the delivery of securities against payment, mitigating principal risk.

c. Central safekeeping services: A CSD keeps securities on behalf of customers, with the aim of ensuring: (i) the integrity of securities issue records, that is, ensure that securities are not accidentally or fraudulently created or destroyed or their details changed (CPSS-IOSCO 2012); and (ii) the integrity of the customer records, that is, the customers' holdings are accurate and not fraudulently altered.

d. Asset services: These services include the administration of corporate actions and redemptions, such as interest payments and dividends.

e. Registrar services: The maintenance of the definite record of legal ownership of securities and issuer services. Although in many countries the CSD fulfils the registrar function, in some countries another entity may serve as the official securities registrar. If the CSD is not the official securities registrar, regular reconciliation between the CSD and the official registrar needs to take place.

The guidance in this paper is based on a combination of theory and country cases. The paper takes into consideration academic literature, relevant international standards and best practices worldwide, notably the CPSS-IOSCO Principles for Financial Market Infrastructures (PFMI), and the most recent results of the World Bank Global Payment Systems Survey. The paper also benefited from IMF and World Bank missions to a range of countries in different parts of the world, specifically the Kyrgyz Republic, Mexico, the Philippines and Tanzania. Further in-depth understanding was gained from interactions with authorities from India, Lithuania and Rwanda.

This paper is targeted at decision makers responsible for the organization of CSDs in a country, but also intends to inform the broader public. Typically, country authorities involved in the decision-making process comprise of ministries of finance, central banks, securities regulators and other relevant authorities. They often work in close consultation and coordination with the private financial sector, including the stock exchange, private operators 
of CSDs, clearing houses, banks, custodians, and broker-dealers. The paper also aims to support policy makers in general, international standard setters and other parties involved in financial market infrastructure issues.

\section{Box 2. Seven Considerations for The Organization of CSD Functions in Developing Markets}

\section{1-Efficiencies through a single CSD}

The concentration of central securities depository services into a single CSD can bring efficiencies in the form of economies of scale and scope. Efficiencies can reduce the costs and complexity of the settlement and safekeeping of securities, and increase the general service level and innovation. However, the potential for efficiencies should be estimated, as low estimates may indicate that a single CSD is not the best solution for some (often larger) markets.

\section{2--Efficiencies through links between CSDs}

In some cases, market efficiencies can be increased through links between multiple CSDs, particularly in large, developed markets. Links between CSDs are often not a useful tool for smaller and/or developing markets due to the high fixed cost of CSDs' IT systems.

\section{3-Efficiencies through competition}

In some cases, market efficiencies can be obtained through multiple, competing CSDs, in particular in large, developed markets. Competition is not a useful tool for smaller and/or less developed markets due to the high fixed cost of CSD's IT systems.

\section{4-The CSD should be able to promote public interests}

The CSD should promote public interests, such as financial stability and financial market development. Also, the CSD should be able to support the implementation of monetary policy, government debt management, and supervision and monitoring of the financial institutions.

\section{5-Financial resources and human resources}

The operator of a CSD should have sufficient resources (financial and human) to support CSD operations.

\section{6-International standards}

The operator of a CSD should be compliant with the requirements laid down in international standards, such as the PFMI, or should be able to comply within a reasonable time frame.

\section{7-Reputation and integrity}

The operator of a CSD should have a good reputation and high integrity. 


\section{Public Function of A CSD}

Country authorities typically have an interest in an efficient and safe CSD, because CSDs have a public function and should therefore be able to address public interests. The most important reasons why CSDs have a public function are:

a. A CSD supports market development through the provision of a central service for clearing and settlement, thereby supporting trading, capital formation and indirectly liquidity in the market. Cirasino et al. (2007) mention that a strong, capitalized, autonomous CSD, with reliable and flexible systems, to expedite settlement of transactions and accessory rights, is crucial for the development of securities markets.

b. In most countries, the CSD is classified as a systemically important infrastructure given its central role in a market. The internationally accepted presumption is that, in principle, all CSDs are systemically important at least in their own jurisdiction (CPSS-IOSCO, 2012). CSDs are central nodes in a financial network of operational and financial exposures through connections between member banks and other financial institutions. A failure in the CSD could disrupt securities markets and cause broader financial and economic instability through propagation of operational or financial losses. An important connection arises from the direct relationships between a CSD and the payment system of the country, for example the real time gross settlement (RTGS) system to facilitate delivery versus payment (DVP) settlement of securities transfers.

c. Many governments rely on markets for government securities to fund their budgets, manage their liquidity, and access information to develop their debt strategy.

Difficulties in CSDs could disrupt the credibility of the government's debt management program and undermine investor confidence.

d. Central banks rely heavily on CSDs to carry out monetary policy through open market operations with government securities or other securities that are held within the CSD. Disruptions in CSD operations could: (i)disrupt the ability of a monetary authority to implement monetary policy effectively; and (ii) fully service the needs of the central bank for liquidity provisioning in the RTGS system, in particular when the RTGS system operates around the clock.

e. CSDs are essential for the timely posting or delivery of collateral for payments, development of the capital market, and other purposes. Central bank's intraday credit, either for monetary policy or payment systems purposes relies heavily on timely availability of collateral.

In most countries, the public function of a CSD for government securities is more prevalent than the public function of a CSD for corporate securities (equities and corporate bonds). The 
five reasons mentioned above typically apply to a CSD for government securities, whereas this may be less the case for a corporate securities CSD. Government securities are issued by the ministry of finance, whereas corporate securities are issues by private sector issuers. Also, government securities are typically used for monetary policy operations, and are considered high quality collateral. Nevertheless, CSDs for corporate securities are not exempted from addressing public interests, as they are critical for the development of securities markets. Also, their central role requires a sound risk profile that supports the stability of securities markets.

Authorities can address the public function of CSDs in various ways. First, authorities can make sure CSDs comply with strict requirements in the areas of governance, risk management and operational reliability, based on sound regulation, supervision and oversight of CSDs, allowing authorities to induce change where needed. International standards, in particular the PFMI, provide a framework for this. Second, authorities can organize CSDs in their country in a safe and efficient manner. This entails decisions about the number of CSDs, the type of securities settled by each CSD, but also whether central banks play a role in the development of capital markets, for example, through contributing to the set-up capital of CSDs or by operating the CSD. Also, public authorities may partake in the governance structure of a CSD, for example, as shareholder and/or through a seat in the board of the CSD. Central banks also can facilitate the cash settlement of securities transactions through the central bank payment system in central bank money. This second set of issues is discussed in the remainder of this paper.

\section{International Practices}

An analysis of international practices may help addressing questions about the organization of CSDs in a country. To that purpose this section provides global data based on the World Bank Global Payment Systems Survey (GPSS). Annex 1 provides a global map of the number of CSDs worldwide.

The GPSS shows a range of different practices in the number of CSDs established and in CSD governance arrangements. Of the 95 countries that provided responses, 55 have a single CSD for all types of securities and 34 have two or more CSDs, each handling only certain types of securities (for example, only government securities or only equities). Only 6 countries have multiple CSDs, each handling all types of securities. Governance arrangements also differ, with varying roles for the public and private sector. Of all CSDs worldwide, 33 percent are operated by the central bank and 67 percent by the private sector.

According to the GPSS differences between regions are substantial when it comes to CSDs. In Europe, and in particular the Euro Area countries, a single CSD is most prevalent, whereas in South Asia preference appears to be for two CSDs at a national level, one for government securities and one for equities (Figure 1). In the Middle East and North Africa, and East Asia and the Pacific all types of CSDs can be found. Governance arrangements also differ greatly, 
with a strong operational role for central banks in Sub-Saharan Africa and a very limited operational role for central banks in the Euro area. The latter can be explained by evolving views about deregulating financial markets in the nineties, which resulted in central banks shifting their CSD activity in connection with government securities to the private sector (Kazarian 2006).

However, the survey data also highlight some global common themes. First, CSDs operated by central banks typically handle only government securities. This reflects the fact that in many countries the central bank is the agent for the ministry of finance, mandated to ensure safe primary and secondary market operations for government securities. In undeveloped or developing markets the central bank is generally the preferred operator due to its reputation, neutrality and risk profile. Central banks can pursue public policy interests such as a nonprofit objective to maintain low fees, and the provision of capital is not conflicted with other shareholder or alternative market development interests. Furthermore, the central bank typically operates the real time gross settlement (RTGS) system for interbank payments, allowing cash and securities settlement under the governance of a single entity and in some cases on the same platform.

Figure 2 shows that of the 138 CSDs incorporated in the World Bank GPSS, 45 were operated by a central bank, of which 38 handled government securities only. In contrast, none of the privately operated CSDs handles only government securities.

Figure 1. Regional differences in the organization of CSDs

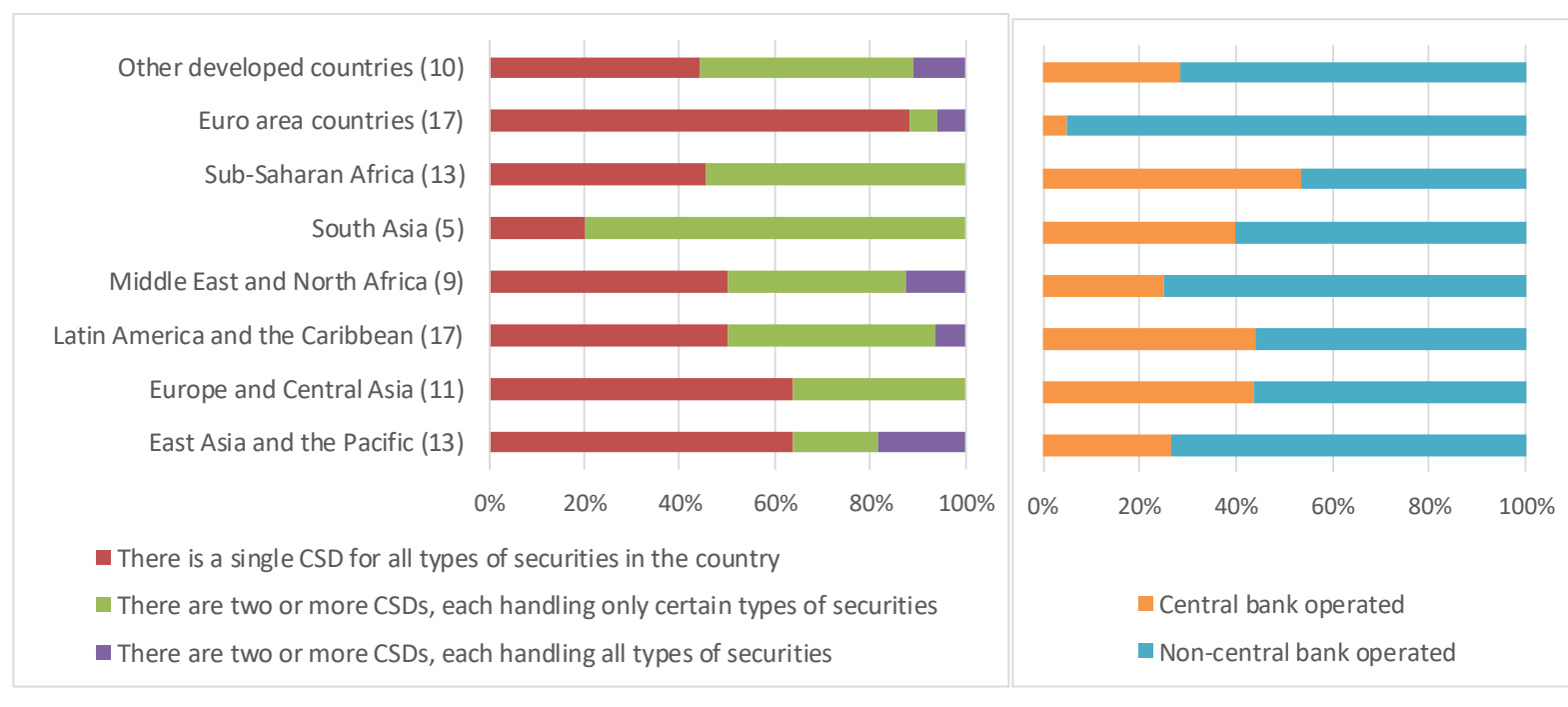

Source: World Bank GPSS 2015

Second, private sector operated CSDs dominate in high-income countries (Figure 3). This illustrates that the central bank is usually heavily involved during the early stages of setting up a securities market, but outsources the operations to the private sector once the market 
develops. Indicators of market development are, for example, a regular and fully subscribed issuance of government securities, a diverse investor base, and an active secondary market in treasury bills. Examples of countries that have outsourced CSD operations include the United Kingdom, Canada and Italy. This outsourcing created single CSDs that handle government and corporate securities (e.g. equities, corporate bonds, and warrants).

Figure 2. Types of Securities settled by Central

Banks and Non-Central

Bank Operators
Figure 3. CSD Governance per income level

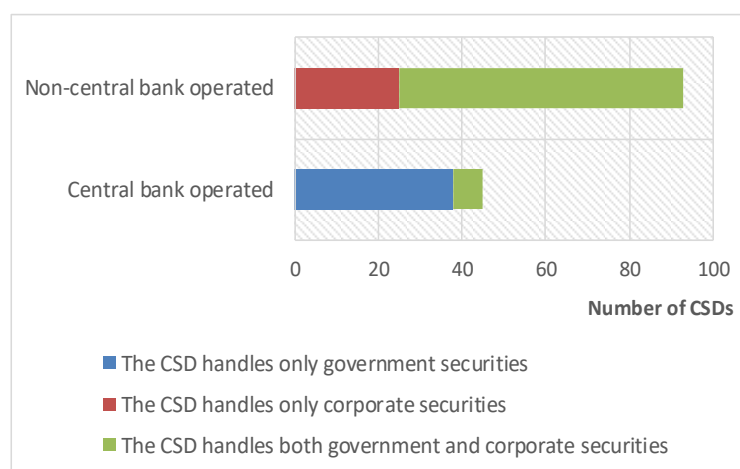

Source: World Bank GPSS 2015, IMF

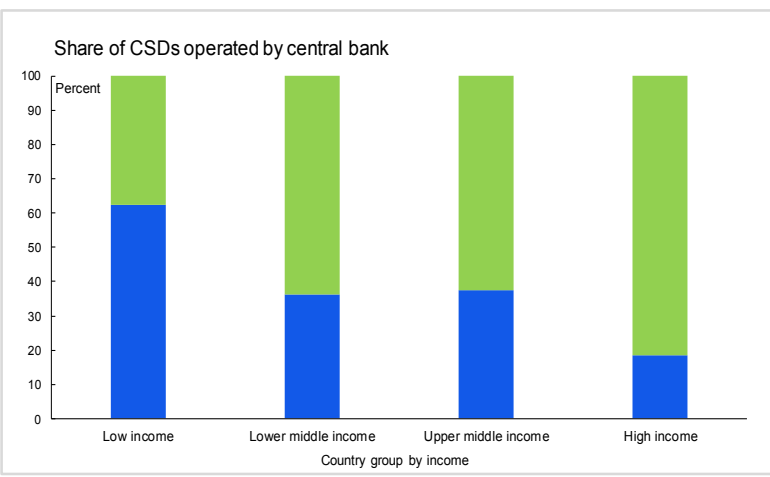

Source: World Bank GPSS 2015, IMF

Third, large markets could be less inclined to adopt a single CSD. Figure 4 displays the relationship between the size of the country (by population size) and the existence of multiple CSDs in the country. A high population size may point to larger markets and somewhat less need to search for further efficiencies. It may explain why, for example, countries with large securities markets, such as China, the United States and India, have multiple CSDs.

Figure 4. Multiple CSDs in large countries

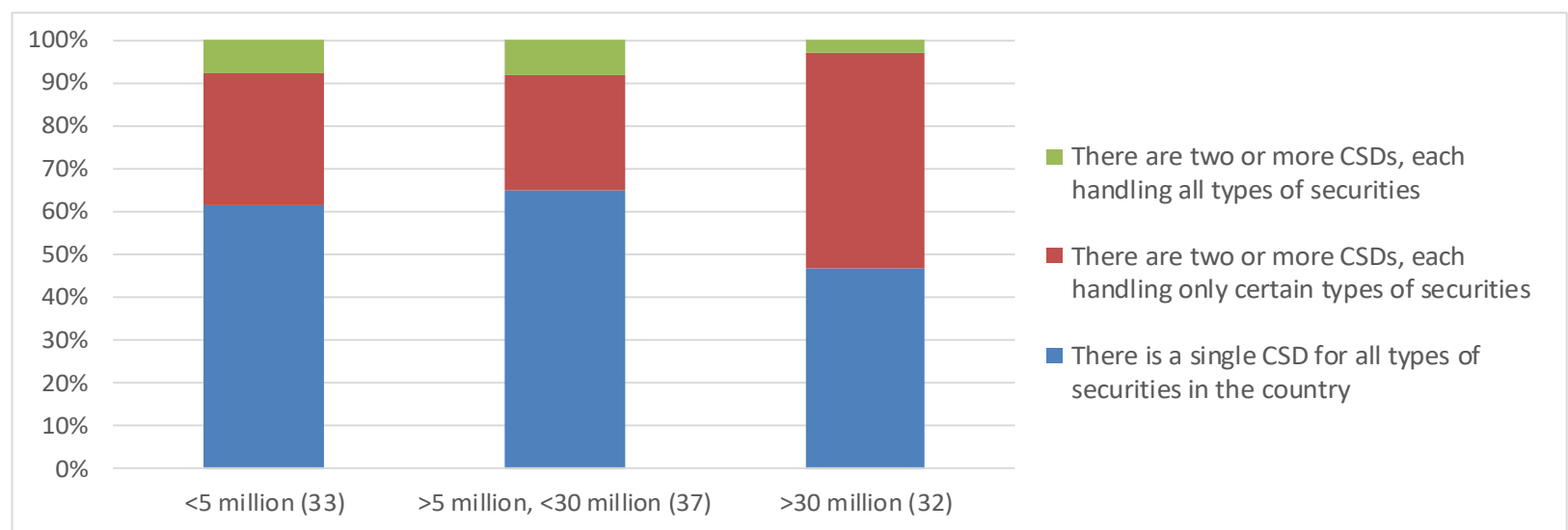

Source: World Bank GPSS 2015 


\section{SEVEn CONSIDERATIONS}

Although international practices are useful to gauge common themes, more guidance is needed to take decisions about the organization of CSDs in a country. This section provides authorities with seven considerations that they may take into account as part of their decision-making process. The considerations can be applied in case where there is no CSD in the country and authorities plan to establish one or more, or when authorities are reconsidering the existing structure. An opportune time to reconsider the organization of CSDs may arise when (i) an existing domestic CSD undertakes a review to modernize its technology; (ii) the central bank reconsiders its role in providing securities and settlement services as a core function; (iii) the market is subject to frauds; or (iv) as part of a coordinated market wide review to develop the securities market.

The seven considerations aim to support decisions about the number of CSDs in the country and their governance structure, i.e., whether to pursue a single CSD or multiple CSDs, and whether the operations and/or ownership should be in public or private hands. The considerations are grouped into 'efficiency considerations' and 'safety considerations' (Figure 5). The considerations are complemented by three cornerstones, which are necessary conditions for the sound and stable operations of CSDs. The seven considerations and three cornerstones are discussed in the remainder of this section and complemented by decision trees.

Figure 5. Considerations and cornerstones for the organization of CSDs

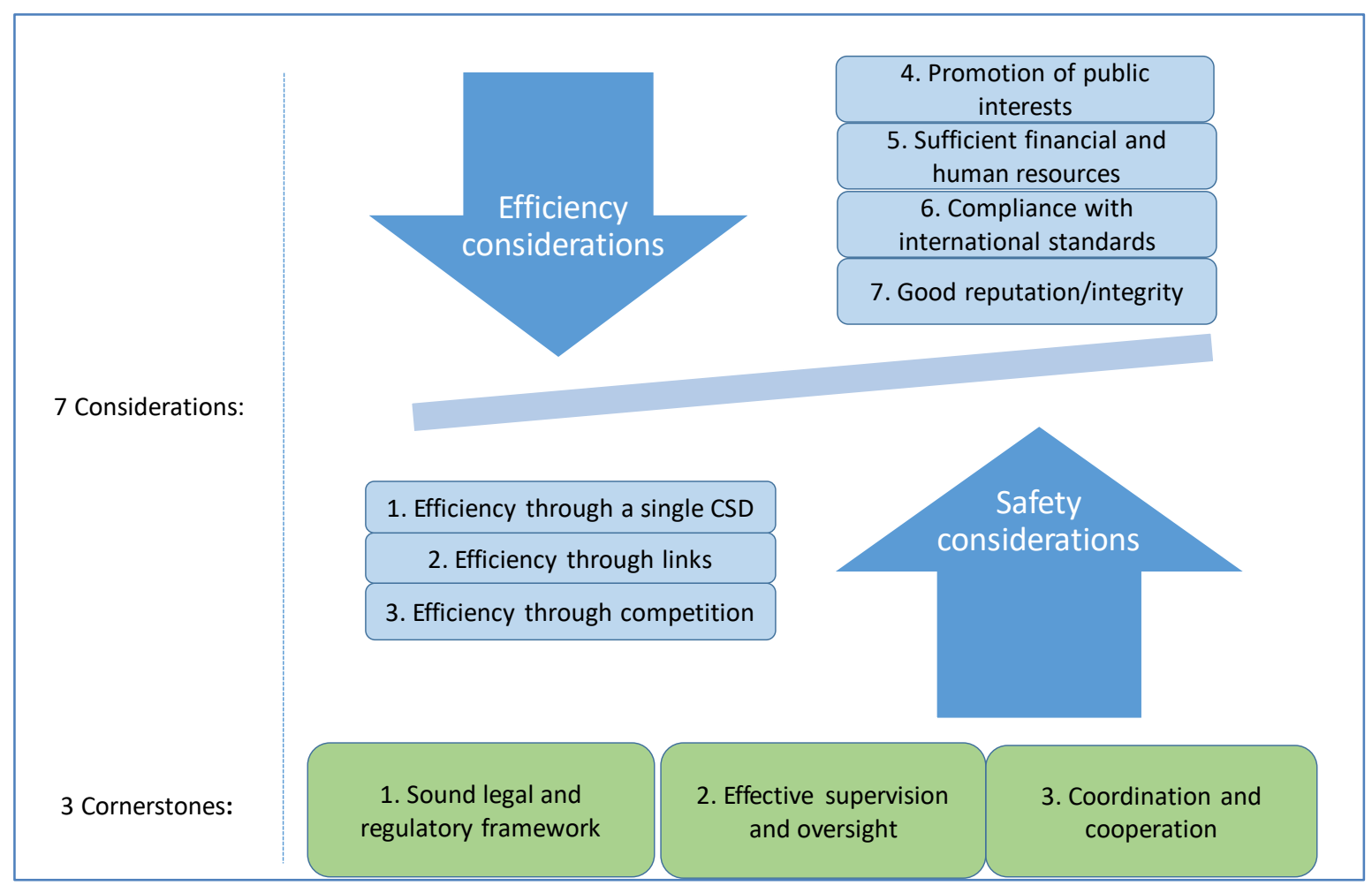

Source: IMF 


\section{A. Single or Multiple CSDs}

The question about the optimal number of CSDs in a country can be directly related to the question how to realize the most efficient CSD(s). Efficient CSDs (i.e., CSDs that optimally use their resources) contribute to the development of securities markets, with higher levels of service, lower prices, and appropriate investments in risk-management systems, which may attract issuers and investors. Country authorities can pursue efficient CSDs in multiple ways, being i) concentration of all CSD activities in a single CSD; ii) links between multiple CSDs; iii) competition among multiple CSDs; and iv) the use of a cross-border CSD. Which way to choose depends on the characteristics of the country as discussed in the considerations below. In making choices about the design and operation, efficiency considerations should be carefully weighed against safety considerations.

\section{Consideration 1-Efficiencies through a single CSD}

The concentration of central securities depository services into a single CSD can bring efficiencies in the form of economies of scale and scope. Efficiencies can reduce the costs and complexity of the settlement and safekeeping of securities, and increase the general service level and innovation. However, the potential for efficiencies should be estimated, as low estimates may indicate that a single CSD is not the best solution for some (often larger) markets.

Theory and practice suggest that the concentration of CSD activities into a single entity and platform may bring economies of scale and scope to a market. This implies that the average cost per settled securities transaction diminishes with the increase in the number of transactions. The IT infrastructure of CSDs is characterized by relatively high fixed costs. The integration of several platforms into a single system that settles many transactions is likely to be more cost-efficient than the juxtaposition of several systems for a single local market (Kazarian 2006). Consolidation of settlement activities into a single CSD may therefore reduce overall costs per settlement transaction, increase market efficiencies and support market development and growth. Box 3 summarizes existing literature about efficiency gains in CSDs.

Economies of scale can be realized using one IT infrastructure for the same type of securities, whereas economies of scope can be realized through one IT infrastructure for different types of securities. Economies of scale occur when multiple CSDs settling the same type of securities merge the CSDs into one entity. In the case of economies of scope, efficiencies occur if a CSD extends its service provision to other types of securities, for example, not only equities, but also government securities and central bank securities. The marginal cost of adding a security type to a single platform is often significantly less than running two systems in parallel. Despite differences between the settlement of equities and government securities, the main IT infrastructure is typically the same for all types of securities. 


\section{Box 3. Literature on Efficiencies in CSDs}

One of the first studies that explicitly addresses economies of scale in CSDs is from the hand of Schmiedel, Malkamäki and Tarkka (2004). This paper investigates the existence and extent of economies of scale in depository and settlement systems. Evidence from 16 settlement institutions across different regions in the world (for the years 1993-2000) indicates the existence of significant economies of scale. The degree of such economies, however, differs by size of settlement institution and region. While smaller settlement service providers reveal a high potential of economies for scale, larger institutions show an increasing trend toward cost effectiveness.

Van Cayseele and Wuyts (2007) confirm evidence of large economies of scale in the clearing and settlement industry by estimating alternative multi-product cost functions of settlement providers and quantify the cost savings potential through economies of scale in European CSDs. They, too, find that especially smaller institutions stand to gain from scale economies, but they also identify the potential for larger operators to grow along a cost-reducing path.

An estimation of potential efficiencies is an important input into decisions about integrating CSD operations. Significant potential efficiencies support the case for (re)organizing CSD functions, whereas minimum or low-cost savings indicate that there is not necessarily an efficiency reason to reconsider the number of CSDs. An estimation may take the following potential cost-efficiencies into account:

a. The number of IT systems, networks and interfaces to be used by market participants, where an integration of CSDs may imply less IT systems, networks and interfaces, resulting in an overall reduction of cost and complexity. It also means a decrease of staff time needed for training and managing new releases and changes to the systems. The choice for a certain CSD technology is instrumental in gaining these efficiencies (Box 4).

b. The number of direct trading counterparties that can be reached, where an integration of CSDs may increase the number of participants joining the same clearing and settlement systems to the benefit of participants (and their clients), which can directly settle transactions with more counterparties. These cost efficiencies relate to the network character of CSDs. For example, integrating settlement systems for government securities and equities combines participants that are typically active in the government securities market, such as primary dealers, banks, and other investors, with participants that are typically active in the equity market, such as broker-dealers.

c. Required support functions, where an integration of CSDs may result in the need for less staff in supporting functions, such as Human Resources, Legal, Finance, and Audit departments. A single CSD also creates a single point for data entry and reporting functions, to the benefit of multiple stakeholders, including supervisors and overseers of the CSD.

d. Market resilience and developmental efficiencies. For example, from an international custodians' perspective, a single point of entry is desirable as it is cheaper, less 
complex and operationally more efficient. Custodians are less likely to service markets with a convoluted CSD structure.

\section{Box 4. CSD Technology Options}

CSD technology is critical for the delivery of both safe and efficient CSD services, and is relevant for many of the seven considerations. Technology, i.e., the software, hardware and networks to process, distribute and store payment, settlement and custody data, should be able to perform without significant disruptions and incidents, ensuring a high availability rate. CSD technology that is not robust will result in the reduction, or breakdown of services provided by the CSD, damage the CSD's reputation and result in system-wide financial losses. Also, CSD technology should be practical and cost-efficient for its users.

Authorities can decide whether to develop in-house systems or buy systems 'off-the-shelf'. Decision makers typically have to consider periodically the relative cost benefits of in-house supported systems against the alternative of vendor CSD systems. Many small to medium CSD operators modernize their CSD services using CSD software from a software vendor as an alternative to in house development. The benefits of using vendor software include: i) vendor software is developed and utilized by other CSDs and does not carry the high risks and testing effort required for in-house systems; ii) the supporting hardware configurations are proven to international standards; iii) experience can be gained from other users of the technology, for example, through forums; and iv) software typically has a shorter time implementation time with lower risk of non-performance.

Technology continues to change as do international sound practices, with distributed ledger technology (DLT) being expected the most revolutionary in the medium to long term. New technology developments typically bring improvements to existing technology in the sense of more robust systems and communication security. Distributed ledger technology, for example, Blockchain, is a new technology in which ledgers - records of transactions or ownership of assets and liabilities - can be maintained and updated securely (called "validation") for an entire network of users by users themselves - rather than by a central agency (He, 2017). Where proponents claim that DLT brings potential safety and efficiency improvements, there are still many issues to be addressed before benefits can be fully realized. DLT may pose new or different risks, such as potential uncertainty about operational and security issues; the lack of interoperability with existing processes and infrastructures; ambiguity relating to settlement finality and the general legal underpinning of the technology; and issues related to data integrity, immutability and privacy (CPMI, 2017).

A single CSD is, however, not necessarily the best option for all markets or countries. Whether to pursue a single CSD depends on the dynamics and size of a country's financial market. In case authorities consider merging two or more CSDs into one, there should be evidence that there is indeed a potential for efficiencies, including lower fees, an improved service level and innovation. Some markets are so large that these efficiencies are relatively minimal and authorities may decide that the cost of integrating CSD operations does not justify the potential gains. The US, for example, is characterized by a CSD for government securities (Fedwire Securities Service) and for corporate securities (Depository Trust 
Corporation), but shows relative low potential for further economies of scale (Schmiedel 2004).

Efficiencies of a single CSD should not be achieved at the expense of the safety of the CSD operations. It is not sufficient to promote a single CSD where the efficiency gain is the sole consideration. It is equally important that the risks are sufficiently mitigated and, in the case of a merger between two or more CSDs, the risk profile of the newly established single CSD should be the same or improved compared to the old situation.

\section{Consideration 2-Efficiencies through links between CSDs}

In some cases, market efficiencies can be increased through links between multiple CSDs, particularly in large, developed markets. Links between CSDs are often not a useful tool for smaller and/or developing markets due to the high fixed cost of CSDs' IT systems.

Efficiencies can sometimes be obtained through links between multiple CSDs. Instead of realizing efficiencies through the creation of a single CSD, existing CSDs may link to increase the scope of securities they are able to settle. A link between CSDs is a set of technical and legal arrangements for the cross-system transfer of securities. A link permits participants in either CSD to trade and settle trades in securities that are held in the other CSD of which the market participant is not a member. Instead, the market participant can access that CSD through its own CSD that acts on his behalf and functions as a 'single gateway'. A link is typically more cost-efficient than the market participant becoming a member in multiple CSDs. Tanzania is a market where the two CSDs have established a link to facilitate the settlement of government securities that are both traded over the counter and on the stock exchange, but are held in only one CSD (see country case Tanzania).

An ultimate way of linking CSDs is through the adoption of the same technology. Using a shared technology platform (hardware and software), would reduce the required capital to service all securities markets with modern CSD systems, reduce the operating costs and therefore accommodate lower fees. Parts of the software could be sectioned off and secured so that CSDs can independently manage their own business interests and promote the different securities markets. This is the most integrated form of links, where participants of each CSD will continue their relationship with that CSD, but all settlements are effected by the wholly integrated systems of the linked CSDs. Georgia is an example of a country that is working towards the adoption of the same technology for its two CSDs. Both the CSD for government securities, operated by the central bank, and the CSD for corporate bonds and equities, operated by the stock exchange, plan to use the same technology platform, which is maintained by the central bank. This approach also reduces the interfaces and dependencies between CSD systems, networks and other core infrastructure, such as RTGS systems, and in that way, reduces operational risk. Having both securities (CSD) and cash (RTGS) legs under one platform operated by a central bank brings a lot of opportunities for settlement automation, including all transactions settling on a delivery versus payment basis in central bank money. At the same time, the different operators are able to develop the rules and procedures in line with their respective mandate and responsibilities. 
Links between CSDs may provide fewer opportunities to benefit from economies of scale than a single CSD, since (some of) the different IT systems remain operating next to each other. Links may also contain operational, credit and other risks, which need to be identified and managed. That is why in most markets, especially smaller and/or developing markets, authorities often choose to merge multiple CSDs into a single CSD, instead of linking the CSDs.

\section{Consideration 3-Efficiencies through competition}

In some cases, market efficiencies can be obtained through multiple, competing CSDs, in particular in large, developed markets. Competition is not a useful tool for smaller and/or less developed markets due to the high fixed cost of CSD's IT systems.

Instead of actively pursuing a single CSD, authorities may choose to stimulate competition among CSDs to achieve greater market efficiencies. Competition is possible between CSDs that in principle offer the same type of services for the same type of securities. The thought is that more competition generally leads to a downward pressure on prices, while stimulating innovation and operational efficiency. In case authorities make a choice for efficiencies through competition, they should provide a legal framework that supports a level playing field, particularly by assuring fair and open access to potential users, price transparency and ensure sufficient incentives to innovate (Giovannini 2003).

The European Union and India provide examples of competition between CSDs. A European example concerns the competition between the two international CSDs, Euroclear Bank in Belgium and Clearstream Banking Luxembourg that offer similar settlement and custody services in a range of similar products to an overlapping set of members. They actively compete, resulting in well-developed services to address customer needs, and competing tariffs. Also, both are potential substitutes in case one of the two CSDs faces operational or financial disruptions. Similarly, in India the two CSDs for the corporate securities market are competing. With the liberalization of the capital market in 1992 competition between stock exchanges, including their CSDs, was introduced to bring efficiencies to the securities market (see India country case).

The question is how much efficiency can be achieved with infrastructures that are typically monopolistic. Competition may work in large, liquid markets, but may be less suitable for smaller markets. The high fixed cost related to the maintenance of multiple CSDs can result in average transaction cost that are relatively high and discourage trading in the capital market. An estimation of potential efficiencies may therefore point out that in many markets, particularly smaller markets in developing countries, competition may not work.

Also, caution is needed as excessive competition between FMIs may lead to a lowering of risk standards. In case competition leads to a deterioration of the CSD's profitability, risk management and service provision, eventually leading to a bankruptcy, authorities may determine that competition harms, rather than benefits the market. 
The decision tree below (Figure 6) summarizes how the various efficiency considerations may result in a choice for the number of CSDs in a country. It provides an example of the order and different steps of the decision process on this matter at a national level. The same steps may be used at a cross-border level, although the decision-making process would entail specific aspects as described in Box 5.

Figure 6. Decision Tree—Single or Multiple CSDs

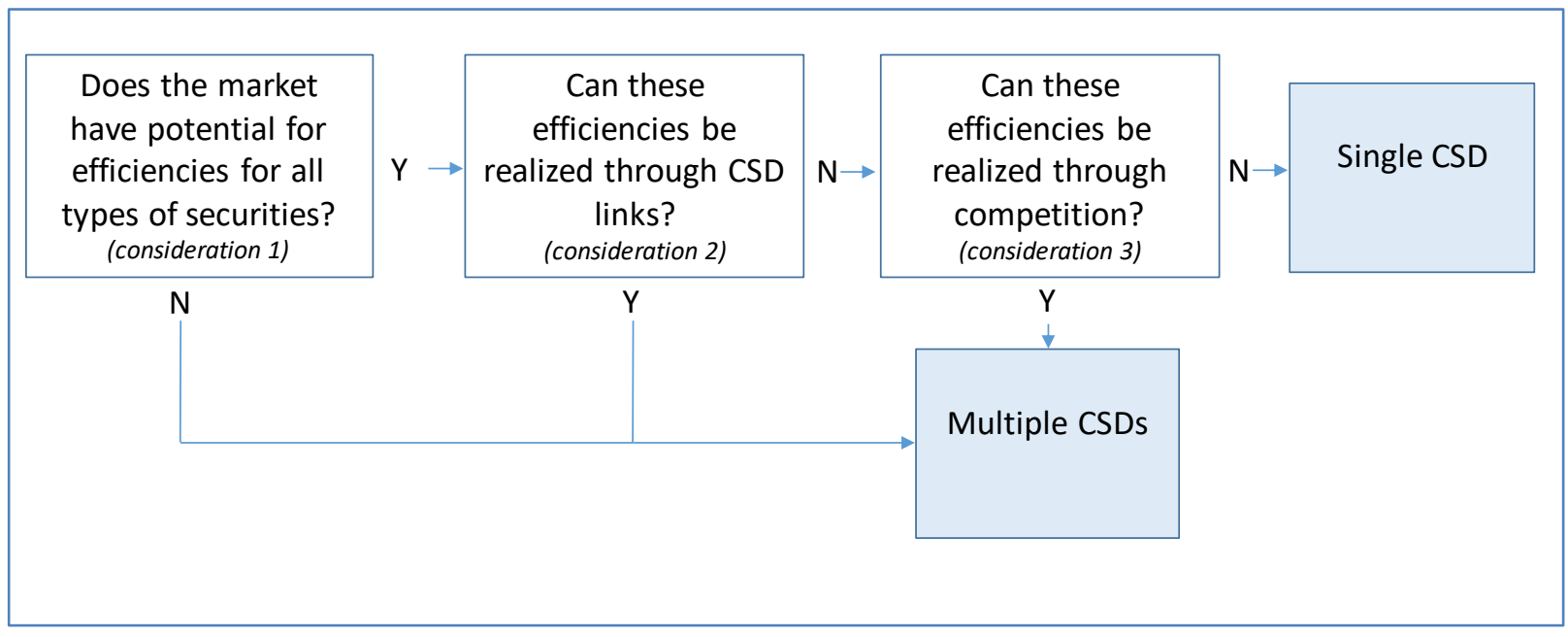

Source: IMF

\section{Box 5. Efficiencies through cross border integration}

Sharing CSD infrastructure on a cross-border basis can deliver efficiencies for CSD technology development and infrastructure. However, the decision to integrate CSD functions into a regional infrastructure should be compatible with sovereignty principles and acceptable cross-border legal, oversight, and governance arrangements.

Authorities may consider partaking in cross-border initiatives to integrate CSDs. Regional integration of CSDs typically aims at enabling cross-border transactions for financial market participants or for their customers, often between the countries within a region (World Bank 2014). Main drivers for integration are: (i) political agreements among countries in a region with the objective to expand trade, increase investment flows among market participants in the region and deepen regional economic and financial integration; (ii) demands of customers and/or participants in national CSDs to reduce settlement cost of cross-border trades and facilitate access to regional and cross-regional markets and services; and (iii) growth orientation through increased foreign investor participation, which deepens and broadens regional financial and capital markets.

Decisions about pursuing efficiencies in cross-border clearing and settlement arrangements can follow the same path as similar decisions at a national level (Figure 6): 
a. Efficiencies can be gained through the creation of a single CSD in the region. A first example concerns the single regional CSD established in the Economic Community of West African States (WAEMU) for the issuance, and settlement of securities issued by several governments in the region. Euroclear S.A. is another example. Euroclear not only operates an international CSD, but also took over seven ${ }^{2}$ national European CSDs. Although each of these national CSDs remained a separate legal entity in its own country, Euroclear's clearing and settlement arrangements allowed for a more efficient settlement of domestic and crossborder securities transactions. A third example is Nasdaq OMX that owns (indirectly, through its holdings in the relevant stock exchanges) a large part of most of the national CSDs in the Nordic and Baltic countries in Europe, realizing efficiencies through harmonized procedures and IT platforms.

b. Efficiencies can be gained through links between CSDs. These can be relatively simple agreements among CSDs to facilitate direct or indirect cross-participation among the participants in each of the CSDs, but also more complex interoperability arrangements involving technical interfaces between the separate operating platforms. Links are regularly established between a local CSD and one of the international CSDs (Euroclear Bank or Clearstream Banking Luxembourg) to allow members of the international CSD to settle transactions in local government bonds with local financial institutions that have accounts in the local CSD and vice versa. Another example is the Mercado Integrado Latinoamericano (MILA) initiative, where the CSDs of Chile, Colombia, Mexico and Peru link through common memberships in each other's CSDs. Also, the Asian Development Bank proposed linking up the existing Asian CSDs, as a possibility to further integrate Asian securities markets (ADB 2014), following the example of the European 'Link Up Markets'. This initiative of eight European CSDs offers direct access to eight markets via a single gateway to reduce costs of post-trade processing of cross-border securities trading in Europe.

c. Efficiencies can be gained through competition. For example, the European Commission3 promotes an efficient internal market through legislation that sets conditions for competition between national CSDs, and improves the level playing field through harmonized requirements and disposition of legal, tax and other barriers (Giovannini 2002). Where the ECB merged settlement activities onto a single platform (Target2Securities) the national CSDs compete for depository services, such as registry and asset services.

In terms of risks, cross-border linkages create new challenges. The cross-border integrated CSD(s) face similar risks as a national CSD. However, because of the cross-border nature of the regional arrangement, these risks may take on new dimensions that may be more difficult to understand and manage in an effective manner than in a single country arrangement (World Bank 2014). Also, the impact of disruptions may be more severe, as disruptions can spread across borders.

\footnotetext{
${ }^{2}$ Belgium, Netherlands, Finland, France, Ireland, Sweden and the United Kingdom.

${ }^{3}$ Interestingly, the European authorities have chosen to facilitate two parallel approaches for achieving crossborder efficiencies in cross-border clearing and settlement: 1) increased horizontal consolidation across CSDs in member states; and 2) increased competition between multiple providers of clearing and settlement services (EU 2009).
} 


\section{B. Public or Private Operator}

The question whether public authorities should be involved in the CSD's governance relates directly to safety considerations. The answer depends on the strength of the (envisaged) private operator and its ability to address public interests through a safe CSD. Safe CSDs are critical for the development and safety of securities markets. Poorly designed and operated CSDs can contribute to and exacerbate financial crises, with disruptions impacting not only the CSD and its participants, but generally financial markets and the broader economy (CPSS-IOSCO 2012). Such weak CSDs hamper the development of securities markets and broader economic growth. In contrast, international experience shows that resilient CSDs can be an important strength - giving market participants the confidence to fulfil their payment and settlement obligations on time, even in periods of market stress - and an important building block in the development of securities markets.

Considerations 4 to 7 support authorities in deciding whether the private sector is capable of operating a safe CSD, or whether (some form of) involvement of the public sector is needed.

\section{Consideration 4-The CSD should be able to promote public interests}

The CSD should promote public interests, such as financial stability and financial market development. Also, the CSD should be able to support the implementation of monetary policy, government debt management, and supervision and monitoring of the financial institutions.

The public function of a CSD requires its owners and management team to explicitly address public interest. This is first a responsibility of the CSD itself (CPMI-IOSCO 2012, Principle 2). Supporting the public interest is a broad concept that includes, among others, fostering fair and efficient markets, strive for solid risk management practices to support financial stability and considering interests of a range of stakeholders, including the CSD's participants, their clients, and authorities. In that regard, investor protection is part of addressing public interests.

If public authorities are of the opinion that the private operator of the CSD is not (fully) capable of addressing public interests, they may partake in the governance of the CSD. This role in the governance of a CSD is in addition to authorities' role in the regulation, supervision and oversight of the CSD, which are described later in this section. Public authorities may consider several options (Russo 2004):

a. The central bank and/or another public authority may be part of advisory groups, which are consulted by the management board of the CSD on specific topics, for example fees, IT reforms and legal issues.

b. The central bank and/or another public authority may occupy seats on the supervisory board and/or the management board to represent the public interest. A seat may be imposed by regulation or be voluntarily adopted by the CSD itself. 
c. The central bank and/or another public authority may take a stake in ownership structure of the CSD. As such, the authorities can determine who will be elected to the board of directors. The authorities are generally assured that the board members they elect will take their interests into account in their deliberations and be responsive to their concerns. Whether the stake is minority or majority stake depends on the legal and regulatory framework in the country, and the authorities' confidence in the ability of the operator to address public interests.

In some cases, authorities may decide that the public sector is best place to fully own and operate the CSD. This may be the case for the CSD for government securities, given its importance for the government debt issuance program and monetary policy implementation. In special circumstances, for example, in case of multiple frauds or other proven inability of the private sector to operate the CSD in the public interest, authorities may decide to operate the CSD for all types of securities.

\section{Consideration 5-Financial Resources and Human Resources}

The operator of a CSD should have sufficient resources (financial and human) to support CSD operations.

An important requirement for a CSD operator is that it has sufficient financial resources to invest in modern IT systems and ensure sufficient capital to cover operational and other losses. A private operator must be able to raise capital for operations through the private sector. Typically, capital is needed to i) fund investments in IT systems, networks, buildings and other to set up or maintain the CSD's operations; and ii) cover potential losses in extreme but plausible circumstances, such as business losses in case of negative income and operational losses. Operational losses can be the result of fraud, errors and system failures. Also, there may be credit risks and liquidity risks to be covered by the CSD's capital.

Equally important, the CSD should have sufficient competent human resources. The CSD needs staff with advanced knowledge and understanding of the different areas of the CSD's operations. Staff should be competent to run a safe and efficient CSD, in line with international standards. In that regard, staff should have knowledge of, and be able to address requirements expressed in the PFMI, to manage legal, credit, liquidity, operational and other types of risks. In order to attract and sustain competent resources, CSDs should remunerate their staff adequately in line with market terms.

The ministry of finance and/or the central bank may decide to provide financial support to a private operator through a stake in the capital of the CSD. In smaller, developing markets private entities often face difficulties raising sufficient capital and realizing an income stream that fully covers the operational costs. This often results in high transaction costs which may ultimately threaten the existence of the CSD. As this hampers market development, public authorities may decide to provide financial support through a stake in the ownership of the company (IMF 2001). In the case of Rwanda, the central bank of Rwanda decided to fully 
own and operate a single CSD for all types of securities to allow the private sector to build financial resources and human capacity (see Rwanda country case). In Lithuania, the public authorities gradually reduced their ownership stake in the CSD, in reflection of strengthened capacity at the CSD, until the CSD was fully owned by the private sector (see Lithuania country case).

Public financing can only be provided in cases where a private operator is a stable and safe entity. Providing financing to an entity with a bad reputation that is not able to operate a safe and efficient CSD, compliant with international standards nor support development of the securities markets, may be considered a waste of taxpayers' money. In this case, it would be better to have the CSD be fully owned and operated by the central bank.

\section{Consideration 6-International Standards}

The operator of a CSD should be compliant with the requirements laid down in international standards, such as the PFMI, or should be able to comply within a reasonable time frame.

A CSD operator should be able to comply with international standards. The PFMI are the main set of applicable international standards, setting a benchmark for safe and efficient systems, while fostering transparency and financial stability. The principles provide guidelines to identify and mitigate risks inherent in a CSD's operations, and promote resilience in the event of major shocks. For example, the CSD should:

a. Address operational risk, including maintaining robust and tested business continuity and disaster recovery arrangements and ensure a recovery of platforms and same day settlement in the event of system hardware, software or network failures.

b. Protect the integrity of the securities issues and minimize the risks related to the safekeeping of securities, to safeguard the rights of securities issuers and investors.

c. Maintain securities in an immobilized or dematerialized form for their transfer in book-entry form.

d. Manage credit and liquidity risks, through investing the CSD's capital at accounts of safe counterparties.

e. Calculate and hold the necessary capital for the CSD's operations, enabling the CSD to cover credit, liquidity, or operational losses in extreme events, including natural disasters and cyberattacks.4

f. Ensure safe cash settlement, preferably through an electronic link with the interbank payment system run by the central bank (which is often a real time gross settlement system).

\footnotetext{
${ }^{4}$ The calculation should include stress testing capital adequacy in extreme but plausible scenarios.
} 
g. Tailor securities settlement arrangements to needs of specific markets, and reducing principal risk through a delivery-versus-payment mechanism and short settlement cycles.

h. Use international communication standards, such as SWIFT, ISO standards and ISIN securities numbering.

A detailed assessment of a potential, new, or existing operator of the CSD shows the level of compliance with the PFMI.5 For example, in case a central bank operates a CSD for government securities and contemplates outsourcing this to the private sector, it should only do so in case an assessment of the operator shows compliance with the PFMI. Where there is no full compliance, this should be achievable within a reasonable time frame. In case the private operator is not expected to achieve compliance within such a time frame, it would be better that the central bank remains operating its existing CSD for government securities. Authorities in the Kyrgyz Republic, for example, decided in 2008, after careful deliberations, not to outsource the government securities CSD to the private sector (see country case of the Kyrgyz Republic).

\section{Consideration 7-Reputation and Integrity}

The operator of a CSD should have a good reputation and high integrity.

The operator of a CSD should have a good reputation and high integrity to provide authorities and market participants with confidence and trust. A good reputation is essential for market participants to be willing to support the entity financially and participate in the development and adoption of IT systems, rules, procedures and agreements. The operator should be of high integrity to provide market participants with confidence that their securities and funds are safe and operational risks are well managed. Integrity includes that the operator supports the central bank and supervisory authorities through the provision of timely access to relevant data and information. The decision tree in Figure 7 provides a summary of how the safety considerations may result in a choice for a public or private operator of the CSD.

\footnotetext{
${ }^{5}$ A template for an assessment is provided in the published in the CPSS-IOSCO Principles for financial market infrastructures: disclosure framework and assessment methodology of December 2012, http://www.bis.org/cpmi/publ/d106.htm.
} 
Figure 7. Decision Tree-Private or Public Ownership and Operations

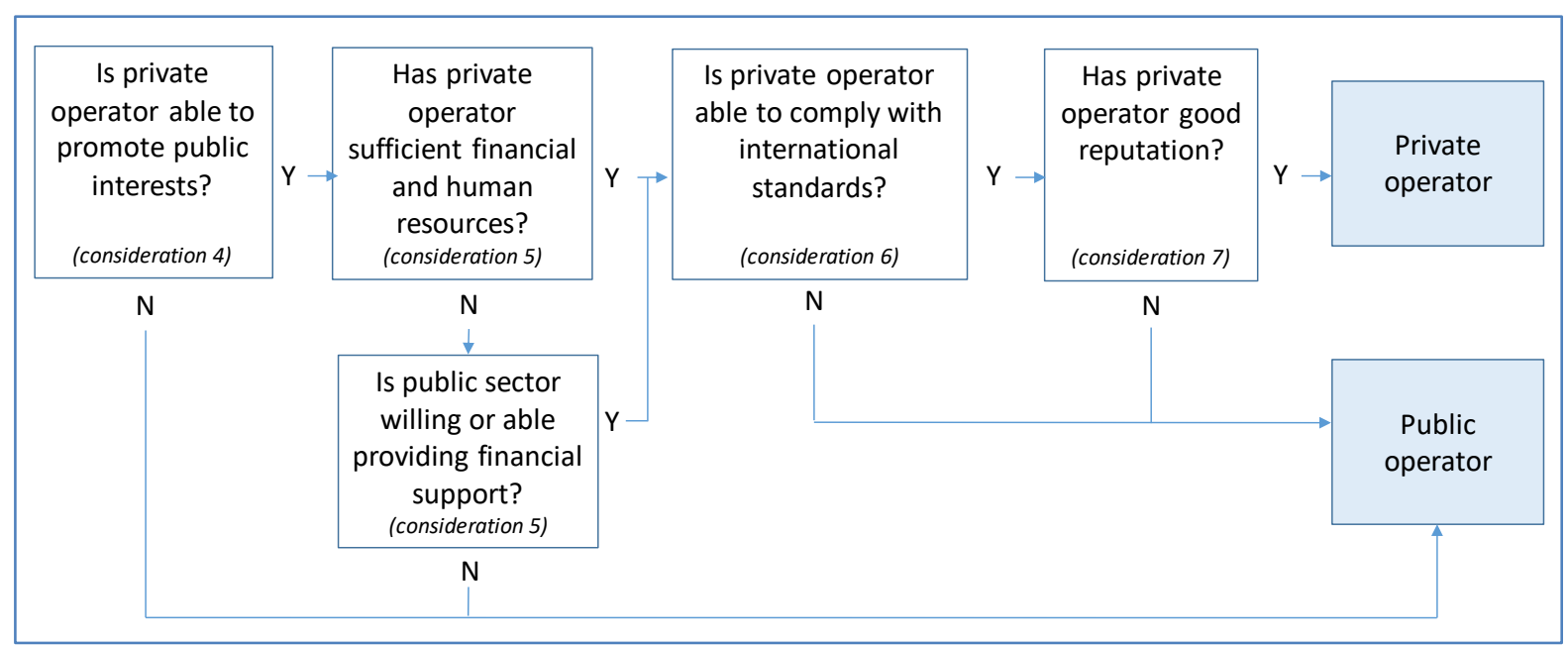

Source: IMF

\section{Three Cornerstones}

Three cornerstones underpin any decision about (re)organizing CSD functions, being i) a sound legal framework; ii) effective supervision and oversight; and iii) cooperation and coordination amongst all stakeholders. With these cornerstones in place, the outcome of the decision-making processes about the best CSD model for a country will most likely result in one or more safe and efficient CSDs that support securities market development and financial stability.

\section{Cornerstone 1-Legal Framework}

A robust legal basis for CSD activities is critical to its overall soundness. The legal basis defines, or provides the foundation for relevant parties to define the rights and obligations of the CSD, its participants, and other relevant parties, such as its participants' customers, custodians, and service providers. If the legal basis for a CSD's activities and operations is inadequate, uncertain, or lacks clarity, then the CSD, its participants, and their customers may face unintended, uncertain, or unmanageable credit, liquidity or operational risks.

The legal framework needs to contain prescriptions related to the authorization of the CSD, its oversight, supervision and regulation and the requirements that the CSD needs to fulfil. Laws and regulations specific to a CSD's activities include those governing its rights and interests in financial instruments; settlement finality; netting; immobilization and dematerialization of securities; arrangements for delivery-versus-payment; collateral arrangements; default procedures; and the resolution of a CSD. The CSD's rules, procedures, and contracts provide detailed agreements in line with the legal framework and international standards. The legal framework also needs to define the legal mandates for authorities, including their information and enforcement powers (CPSS-IOSCO 2012). 


\section{Cornerstone 2-Regulation, Supervision and Oversight}

Regulation, supervision and oversight of CSDs are critical to ensure that a CSD addresses public interests. While each individual CSD is responsible for addressing public interests, and in a broader sense, comply with the PFMI, regulation, supervision and oversight by one or more financial sector statutory authorities is necessary to ensure observance with the requirements and induce change if needed.

In many countries CSDs are regulated and supervised by central banks and securities regulators. Securities regulators are typically concerned with the orderly functioning of the securities market and therefore regulate and supervise stock exchanges, clearing and settlement institutions and securities market participants, based on a securities market law. In addition, central banks oversee CSDs based on the central bank law and often a dedicated national payment and settlement systems law. The linkages between monetary policy, operation of the payment system, and the economy's liquidity needs have all quite naturally cast upon the central bank the role of overseer of financial market infrastructures, including CSDs, as an extension of its reserve money-issuing function, to ensure financial stability.

Cooperation among authorities is essential, in particular if a CSD is under the responsibility of multiple authorities, or if multiple CSDs with different authorities are active in the country. Typically, a framework for cooperation is agreed between the authorities. The authorities can consider a variety of approaches, including information sharing arrangements and coordination of responsibilities. Exchanges of views and information may be conducted by holding regular meetings. Good practice requires that authorities sign a Memorandum of Understanding, whereby both undertake to cooperate in carrying out their tasks with due respect to their mutual responsibilities, and agree to provide each other with routine or ad hoc information as may be necessary to help each party in the implementation of its tasks. In addition, authorities may meet regularly on a technical and higher level for policy coordination purposes. Examples of topics to discuss are any system changes, changes in the CSD rules, joint PFMI assessments, and the development of an orchestrated approach toward crisis management and default plans.

In case the central bank is the owner/operator, as well as overseer of the CSD, conflicts of interest need to be addressed. A central bank can be conflicted in case it oversees multiple CSDs with different operators, one of which is the central bank itself. The central bank can minimize the conflict through transparency about its requirements and applying them equally to the different CSDs. Conflicts can also arise internally within the central bank, in case a central bank director must choose between the interest of the unit operating the CSD and the unit overseeing it. These conflicts should be managed by establishing separate reporting lines for the operations and oversight departments to the board of the central bank.

In case the central bank owns a CSD, interests of other stakeholders need to be addressed through alternative means. Possible mechanisms for involving other stakeholders are 
stakeholder representation on the board (in case the CSD is a private company), establishing user committees and the use of a public consultation processes.

Cross-border integration of CSDs impacts the supervision and oversight of national authorities. A cross-border or regional CSD will change the role of the central bank and other public authorities when the CSD is not located in its country. Joining a cross-border CSD, located outside the country, reduces the capacity of national authorities to supervise and oversee the CSD. Public authorities will need to make sure that they are still able to fulfil their legal mandates even though the CSD is no longer located in their own territory. Ways to this are:

a. Recognize a foreign CSD under the central bank law and/or securities market law.

b. Partake in a joint oversight and supervision arrangement with the home regulator.

c. Partake in joint crisis management arrangements to ensure to obtain timely information in case of crisis. Authorities should be able to understand how shocks can (potentially) affect the financial stability in their country, and undertake mitigating actions.

\section{Cornerstone 3-Cooperation and Coordination}

Decisions about the organization of $\operatorname{CSD}(\mathrm{s})$ can only be successfully implemented if all the relevant public authorities as well as private sector are involved. It is important that each authority's requirements are recognized and included in the CSD infrastructure design, development and operation. The private sector, including the stock exchange, banks, custodians, broker-dealers and other stakeholders, are also essential in all phases of the decision-making process. They provide key knowledge in the early exploratory phases and are important executors in the implementation phase. Public authorities should therefore set up a project structure, outlining roles and responsibilities throughout the decision-making process and implementation phase.

A National Payments Council (NPC) or similar forum is a useful platform to facilitate communication between all public and private stakeholders. In several countries involved in modernization of payment and settlement systems such councils have been established. They are often led by the central bank and have a wide representation. The NPC aims to support the achievement of sound and efficient payment and securities clearance and settlement systems in the country. It can also serve as a forum for cooperation as it gives representation to all the stakeholders of payment and securities clearing and settlement systems, e.g. the central bank, the securities regulator, the banking supervisor, the ministry of

Finance/Treasury/Economics, the bankers' association and commercial banks, the non-bank financial institutions, the clearing houses and payment service providers, the stock exchange, the CSDs, and the end-users. 


\section{OUTCOMES OF DECISION MAKING—4 MODELS}

The key challenge for authorities is combining safety and efficiency considerations to find the best model for their country. Authorities will need to find appropriate tradeoffs between potential efficiency gains and safety issues. This requires sound judgment, and a good understanding of the country's securities markets and the strength of potential CSD operators. Although a single CSD can be the most efficient solution from a cost-perspective, authorities may consider that the private sector CSD is not ready to take onboard government securities and therefore decide that the public interest is best served by having two CSDs in the country, a private CSD for corporate securities and a public one for government securities. 6 Other authorities may consider that the private sector CSD is ready to address all public interests related to government securities and decide to create a single CSD run by the private sector, while subjecting the single CSD to adequate supervision and oversight. Annex 2 contains a decision tree that combines the seven considerations and may be used by authorities as a tool to navigate the different considerations.

\section{Four Main Models for the Organization of CSDs in a Country}

\begin{tabular}{|c|c|c|c|c|}
\hline & \multicolumn{2}{|c|}{ Private Operator } & \multicolumn{2}{|c|}{ Public Operator } \\
\hline Single CSD & \multicolumn{2}{|c|}{$\begin{array}{l}\text { Model A for: } \\
\text { - } \quad \text { All market sizes, but not } \\
\text { necessarily the largest markets } \\
\text { - With strong private sector } \\
\text { operator }\end{array}$} & \multicolumn{2}{|c|}{$\begin{array}{l}\text { Model B for: } \\
\text { - } \quad \text { Small markets } \\
\text { - With strong public-sector } \\
\text { operator and weak private sector } \\
\text { operator }\end{array}$} \\
\hline Multiple CSDs & $\begin{array}{l}\text { Model C for: } \\
\text { - Large, liquid } \\
\text { markets } \\
\text { - With strong } \\
\text { private sector }\end{array}$ & $\begin{array}{l}\text { Model D for: } \\
\text { - } \quad \text { All marke } \\
\text { the smalle } \\
\text { - With stro } \\
\text { private se }\end{array}$ & $\begin{array}{l}\text { zes, except } \\
\text { narkets } \\
\text { ublic and } \\
\text { operators }\end{array}$ & $\begin{array}{l}\text { Model E: } \\
\text { - This model is in } \\
\text { theory possible, } \\
\text { but not } \\
\text { recommended. }\end{array}$ \\
\hline
\end{tabular}

Authorities' decision-making process may result in one out of four main models, with different safety and efficiency features:

a. Model A stands for a single CSD, with the private sector operator having a full or majority stake in the CSD's capital. Model A is a good model for all market sizes,

\footnotetext{
${ }^{6}$ A technical aspect related to this is that settlement practices for government and corporate securities typically differ. The nature of equity transactions is high volume and low value. They tend to be settled on a single or multiple net basis during and/or at the end of the day. On the other hand, government securities are typically traded 'over the counter' and tend to be high value low volume traded. In developed markets these transactions typically settle on a real time gross settlement basis, reflecting the liquidity requirements of banks.
} 
although efficiencies may be less prevalent in the largest markets. Efficiencies are realized through economies of scale and scope in single CSD, whereas the private sector operator is able to promote public interests, through sufficient financial and human resources, observance of international standards, and a high reputation and integrity.

b. Model B represents a single CSD, with a full or majority stake of the public sector. This model is well suited for small markets, with a strong public-sector operator that steps in to (temporarily) support the development and stability of the securities market, in the absence of a strong private sector operator with sufficient financial and human resources, which is not able to sufficiently address public interests. In this model, efficiencies are realized through economies of scale and scope in a single CSD. Safety is addressed through the dominating role of the public operator.

c. Model $\mathrm{C}$ represents a country with multiple CSDs, all operated by the private sector. This model is well-suited for large, liquid markets with a strong private sector. Efficiencies are gained through competition between multiple private sector operators and a legal framework that ensures a level playing field. Safety and stability are pursued through strong operators that are able to promote public interests, have sufficient financial and human resources, observe international standards, and have a good reputation and high integrity.

d. In Model D two or more CSDs are operated in the country. One is operated by the public sector, whereas the other $\operatorname{CSD}(\mathrm{s})$ is/are in the hands of the private sector. The model is suitable for all market sizes, except the smallest markets, and requires strong public and private operators. Efficiencies can be gained through links and competition between private-sector operated CSDs. Efficiencies should not be realized through competition between a privately owned and a publicly owned CSD. For that reason, it is recommended that publicly and privately operated CSDs do not service the same securities. In this model safety is ensured through operators that are able to promote public interests, have sufficient financial and human resources, are able to observe international standards, and have a good reputation and high integrity.

In theory, Model E is a possible outcome, with multiple CSDs, all operated by the public sector of a country; this model is generally not recommended. There are efficiency gains in centralizing securities settlement and safekeeping in one public entity. In practice, authorities have come to different models as national features differ. The next section zooms in on a few countries that represent different models. 


\section{COUnTRY CASES}

\section{A. India: efficiencies through competition in the stock market}

India represents Model D, and is a good example of a country that has pursued efficiencies through competition between two CSDs in the corporate securities market. The securities settlement in depository systems in India are organized along the lines of different types of products, with one CSD for government securities and two CSDs for corporate securities:

a. Government securities are settled in the books of the Public Debt Office system of the Reserve Bank of India (RBI). The settlement of the cash leg of every securities transaction takes place in the RTGS system of the RBI, and the securities leg in the Subsidiary General Ledger Account, maintained by RBI. The RBI is the regulator and overseer, based on the Government Securities Act and the Payment and Securities Settlement Act, 2007.

b. Corporate securities are settled and held in one of the two privately operated CSDs, the National Securities Depository Limited (NSDL) and the Central Depository Services (India) Limited (CDSL). Securities traded on any stock exchange i.e. the National Stock Exchange (NSE), Bombay Stock Exchange (BSE) or the Metropolitan Stock Exchange of India (MSEI) are settled and held in dematerialized form with the National Securities Depository Limited (NSDL), or the Central Depository Services Limited (CDSL) and the choice of the CSD is determined by the investor. There is a real-time link between both CSDs to facilitate inter-operability. The NSDL is owned by the NSE to the extent of 24 percent and the remaining shares are mainly held by commercial banks. The CDSL's promoter is the BSE with a 24 percent stake. Other shareholders in the CSDL are commercial banks and financial institutions. The CDSL got listed on June 30, 2017, resulting in a reduction of the BSE stake to 24 percent. Both stock exchanges use commercial banks to settle the cash leg of securities transactions. The Securities and Exchange Board of India (SEBI) is the regulator and supervisor of these stock exchanges, including its clearing and settlement systems, based on the Securities and Exchange Board of India Act, 1992.

With the liberalization of the capital market in 1992 competition between stock exchanges, including their CSDs, was introduced to bring efficiencies to the securities market. The BSE is one of Asia's oldest exchanges and was the dominant exchange for various decades. In the nineties, the SEBI created an enabling environment for the development of new stock exchanges, to enhance technology, transparency and non-discriminatory access. This resulted in the establishment of the NSE. The NSE offered electronic trading through modern technology with access criteria that ensured equal access to all brokers that were able to comply with the criteria. Thus, competition among stock exchanges, including CSDs, significantly changed the trading landscape and brought cost reductions and innovations. It made NSE the largest stock exchange in the country, while competition with the BSE prevents complacency. The dematerialization of securities further increased the efficiency of the market. 
Authorities are not seeking further economies of scale through an integration of the CSD for government securities and the CSDs for equities. However, the RBI has announced measures to enable the seamless movement of securities from the RBI ledger to the NSDL and CDSL and vice-versa.

\section{B. Kyrgyz Republic: two CSDs for stability reasons}

The Kyrgyz Republic is also an example of Model D. This country case shows that authorities initially considered to move towards a single CSD run by the private sector, to benefit from economies of scale and scope, but did not push this model forward for safety and stability reasons.

In the Kyrgyz Republic, two CSDs are being operated: one for government securities and one for corporate securities. The Ministry of Finance is mandated by law to act as the fiscal agent of the government, which includes responsibilities to appoint the clearing and settlement agent for government securities. The Ministry of Finance has in that regard appointed the National Bank of the Kyrgyz Republic (NBK) as its fiscal agent, which fully owns and operates the CSD for government securities. The CSD for corporate securities is a for-profit Joint Stock Company (JSC) since 1997. The shareholders in the JSC CSD are commercial banks, brokers, the Kyrgyz Stock Exchange (KSE), and several other private parties.

Initial plans to develop a single CSD operated by the KSE were not continued. To benefit from efficiencies of scale and scope the JSC CSD was working towards becoming the single CSD for all securities traded in the Kyrgyz Republic, including for government securities. Similarly, the KSE was working towards becoming the single trading platform for all securities. The necessary technology for trading, clearing and settling government securities was already in place. The plans were not pursued, because the KSE and JSC CSD were found to be needing more time to develop and mature to be able to address public interests. For example, cash settlements were conducted through commercial bank accounts, whereas settlement of corporate securities could take up to three days due to communication procedures between the 18 private registrars and the CSD. Also, capital markets were still in an early stage of development, making it premature for the central bank to outsource the issuance, clearing and settlement arrangements for government securities to the private sector.

The KSE and JSC CSD are subject to further measures to strengthen their governance and risk management frameworks. An important measure to reduce KSE's exposure towards commercial banks, has been KSE's request to the NBK to allow it to settle through the RTGS system. In 2016, a Decree was issued for the Government State Property Department to take a shareholding in KSE of at least 33.4 percent and a shareholding in the JSC CSD of at least 50 percent, with the aim to enhance their risk profile and financial capacity. The KSE and the JSC CSD require investors to deposit sufficient funds (at least one day in advance) into the appropriate bank accounts, and to hold securities in the CSD sub-register for faster and more 
efficient settlements. Further measures are foreseen to bring the JSC CSD into full compliance with international standards and good practices.

\section{Lithuania: gradual sale of public stake in CSD}

Lithuania represents Model A and is an example of a country where the public sector reduced its ownership gradually, from a majority stake, to a minority stake, and ultimately entrusting the private sector operator with the full ownership of the single CSD in the country.

Lithuania established a single CSD in 1994. Lithuania, like other countries in the region, became independent from the Soviet Union in the early nineties. Authorities subsequently established the National Stock Exchange to manage the mass privatization of former state companies. The stock exchange initially incorporated a central depository, but in 1994 the Central Securities Depository of Lithuania (CSDL) was established as a separate company. In that same year, the Government started issuing government securities and the central bank was appointed as government agent, responsible for the management of government debt. Authorities considered the possibility of establishing a separate CSD for government securities (as was done in Latvia), but it found no rationale as participants in the government bond market were the same as in the capital market.

The single CSD was largely owned by the public sector. Based on their financial capacity the National Stock Exchange contributed 8 percent to its equity capital, the Government contributed 32 percent, and the Bank of Lithuania (BOL) 60 percent. The Board of the CSDL included representatives of these shareholders, using a ratio that mirrored the capital structure. In addition, the Lithuanian Securities Commission supervised the CSDL as an institution (prudential supervision) and the BOL performed the oversight of CSDL's securities settlement system. Both institutions formalized their cooperation arrangements through an MOU.

The CSD's ownership structure changed over the years from a largely public company to a fully private company. With the development of the market, and increased capacity at the CSDL, the stock exchange and the Government decided to sell their stake. In 2004 they sold their stake to NASDAQ OMX (32 percent NASDAQ OMX Helsinki Oy and 8 percent to NASDAQ OMX Vilnius), a private financial infrastructure group. The BOL kept its majority stake of 60 percent. It also kept participating in CSDL's Board, providing the chairman and two members. Two other members were provided by NASDAQ OMX. The focus of the BOL in the Board was to ensure the safety and efficiency of the system and financial soundness of the organization.

When Lithuania introduced the euro, the BOL decided that further participation in the governance of CSDL was no longer necessary. It found that developments in Europe, focusing on competition and consolidation, did not fit the central bank's core responsibilities. It decided to concentrate on main central bank tasks and sell its share, also because there was comfort at the side of the BOL that NASDAQ OMX was a sufficiently stable and reliable operator, placing the necessary emphasis on sound risk management practices. As per 
January 2013 the stake of the BOL was reduced to zero and the BOL no longer participated in the Board. The BOL is now 'only' involved at arm's length as regulator and supervisor of the CSDL. Since the merger between the BOL and the Lithuanian Securities Commission in 2012, there are two different BOL units responsible for the CSDL: one is responsible for oversight of the securities settlement system, and the other for the prudential supervision of the CSDL and for supervision from a securities market regulator's perspective.

\section{Mexico: a single CSD operated by a private entity}

Mexico also represents Model A, and is a good example of a country that sought to benefit from economies of scale and scope to help develop the securities market and the broader financial system. Authorities rely on regulation, supervision and oversight, as well as cooperation and coordination with the private sector, to address public interests.

In 1995, the two CSDs in Mexico merged into a single CSD operated by the Mexican Stock Exchange. Prior to 1995, the Mexican Stock Exchange operated the CSD for corporate securities (Indeval), and Banco de Mexico (BdM) operated the CSD for government securities. BdM sought to introduce a delivery versus payment model to reduce principal risk in the settlement of securities transactions. Instead of investing in systems for its own CSD, BdM chose to improve efficiencies in securities settlement by exploiting the economies of scale that could be achieved through using a single CSD. Indeval was the preferred single settlement system subject to a range of preconditions and measures to address the BdM, MOF and the National Banking and Securities Commission (CNBV) systemic and public interest safety concerns.

Both CNBV and BdM have a clear autonomous legal mandate to supervise and monitor Indeval under the Securities Market Law and Payment System Law respectively. Both supervisors are actively engaged in Indeval's supervision and oversight, focusing on Indeval's resilience, security, integrity of data and safety. They work harmoniously together to avoid overlaps or gaps. CNBV's supervision covers (i) the CSD's role and impact on securities market development; (ii) the financial capacity of the CSD; and (iii) changes to the CSD's fee schedule. BdM's oversight reflects the importance of the CSD to support monetary operations and provide system liquidity. Since the Payment System Law is applicable to the securities settlement system of Indeval, BdM has powers to request information and authorize or request changes to the internal regulations of the CSD. BdM has powers to veto Indeval's fee schedule and could also design and implement mandatory adjustment programs aiming at eliminating deficiencies.

BdM has powers to foster the proper functioning of the payment systems based on regulations the BdM issues under the Banco de Mexico Law and Payment System Law. With these powers, BdM approves which CSD can link to the SPEI, which is BdM's RTGS system. On the other hand, MOF approves which CSD can provide settlement and custody services for government securities. BdM continuously monitors the settlement activity in Indeval. It was actively involved in the establishment of the single CSD and over the years 
required improvements to the systems and procedures of Indeval, with the aim to support financial market liquidity and development of the government securities market. For example, Indeval's systems were modernized in 2008 with new functionality with settlement in near real-time (two-minute cycles with a netting algorithm to optimize liquidity). Many participants in Indeval, including broker-dealers, have SPEI accounts, which enhances settlement efficiency.

$\mathrm{BdM}$ retained a 2.43 percent shareholding in Indeval and has a seat on the Board as an independent member. The BdM can use its position to engage in Indeval's operations and to influence Board decisions, for example, to adopt safe practices that are consistent with the PFMI. Of high importance are decisions on business continuity, system and data security, fraud prevention, and technology.

Under the Securities Market Law a CSD must receive a concession from the MOF to operate as a CSD. The concession is provided on a discretionary basis, hearing the opinion of the CNBV and BdM, and allows a private sector company to provide a public good with conditions attached. These conditions include requirements to (i) maintain sufficient financial capacity to operate a CSD; (ii) provide access to services on a non-discriminatory basis; (iii) charge reasonable fees on a non-discriminatory basis; and (iv) provide custody and settlement of securities with the appropriate level of service. The MOF, at the proposal of CNBV or BdM, or otherwise having heard the opinion of such authorities, may revoke the concession if the CSD breaches any of these conditions or the law.

The efficient and safe operations of the privatized single CSD model is maintained by the high degree of transparent communications and co-ordination among stakeholders.

Stakeholders include the regulators, Indeval, individual market participants and the various market associations such and the Bankers Association and Brokers Association. There is an active use of specialized committees and work groups to address specific issues.

\section{E. Philippines: Ministry of Finance involved in governance of CSD}

The Philippines represent Model D, with the special feature of the Ministry of Finance being the owner of the CSD for government securities, and not the Central Bank.

In the Philippines government securities are held in the state-owned Registry of Scriptless Securities (RoSS) system. The RoSS is operated by the Bureau of the Treasury (BTr). The BTr is an agency of the Philippines Department of Finance, which is vested with the authority to act as the fiscal agent of the government. The RoSS supports cash settlement through the Philippine Payments and Settlement System (PhilPaSS), which is the real time gross settlement (RTGS) system owned and operated by the Bangko Sentral ng Pilipinas (BSP).

Corporate securities are held in the privately-owned Philippine Depository and Trust Corporation (PDTC). The PDTC is a majority owned subsidiary of the Philippines Dealing System Holding Corp. that is owned, on its turn, by the Philippines Stock Exchange (PSE) 
with 21 percent, the Singapore Stock Exchange 20 percent, banks 28 percent; and the remaining 31 percent (in small proportions) by various companies. The PDTC provides safekeeping, clearing and settlement services for corporate bonds, government securities, repos, bank notes and OTC equity transactions. It serves as a register for all corporate bonds, bank notes and some equities that clear and settle through the PDTC. Payments are settled through the PhilPass. The PDTC also settles equities traded on the PSE. The cash leg is settled through 8 commercial banks.

The BSP is tasked with the objective of maintaining price stability and creating a conducive environment for sustainable economic growth; it has no role in the ownership and operations of the CSDs. The BSP was fiscal agent until 1993, when this role shifted to the BTr, including the operations of the CSD. BSP's current role in relation to CSDs comprises settlement of the cash leg of the securities transactions in PhilPaSS, jointly supervising the PDTC with the Securities and Exchange Commission (SEC), an agency of the Philippines Government. The RoSS is not supervised or overseen by the BSP and SEC. The BTr, as an attached agency of the Department of Finance, is vested with the sole authority to administer and operate the RoSS and to act as the fiscal agent of the government.

Authorities are reconsidering the current structure. The original plan in the nineties, for the concept of a Philippine CSD, was to have all securities housed under one roof. However, for various reasons a single CSD was never established and separate initiatives, influenced by market participants' interests, resulted in the current structure with two CSDs. Recent developments, such as the wish of the clearing subsidiary of the PSE to settle the cash leg of

equity trades into the PhilPaSS, and PSE's wish to expand, may lead to new roles of the PSE and/or the BSP. Efficiency gains are being sought, however, the main driver for the authorities is the conviction that efficiency not only relates to cost, but also to efficiency benefits resulting from the effective management of risks.

\section{F. Rwanda: a single CSD operated by the central bank}

Rwanda represents Model B. The Central Bank decided to establish a single CSD to benefit from economies of scale and scope, with a full ownership of the Central Bank given the small market size and nascent stage of the market.

Rwanda has a single CSD which holds both government and private securities. The single CSD is owned and operated by the National Bank of Rwanda (BNR). The BNR is tasked with the primary responsibility of formulating and implementing monetary policy as well as maintaining financial stability. In this regard, the BNR was also given the important responsibility of driving the modernization of the financial sector in Rwanda under the Financial Sector Development Plan (FSDP). In addition, the BNR has the legal mandate to regulate, supervise and oversee payment systems, CSD and securities settlement systems. This mandate is entrenched in the provisions of the Central Bank Law, the National Payment Systems Law (2010) and Law N ${ }^{\circ} 26 / 2010$ of 28/05/2010 governing the holding and circulation of securities. 
In considering the establishment of the CSD for the country, the Government of Rwanda, regulators and the financial market industry made a decision to have one CSD that would hold both Government and public securities. This decision was mainly based on the following considerations: a) given the market size, the existence of more than one CSD could not be justified; b) the Rwanda Stock Exchange (RSE) was at a nascent stage with limited resources to own and manage such an operation, whose implementation was critical in supporting the dynamic management of collateral in the real time gross settlement (RTGS) system and the settlement of securities on a delivery versus payment basis. Prior to the establishment of the current CSD, the RSE depository services were outsourced to the Central Depository and Settlement Corporation (CDSC) of Kenya for a year.

With the implementation of the Rwanda Integrated Payment Processing System (RIPPS) in 2011, the BNR authorities decided to establish one platform to support the RTGS system operations, automated clearing house $(\mathrm{ACH})$ and CSD operations. The CSD is linked to the RTGS component to facilitate delivery versus payment model one in the settlement of both private and public securities. Despite this arrangement, challenges still exist stemming from the fact that the RSE has no trading platform; hence all post trade transaction are posted manually into the system. Plans are underway for the RSE to use the trading platform that is being developed under the East African Community (EAC) regional initiative that is looking at linking the stock exchanges and the CSDs in the region

The Rwanda Capital Markets Authority (CMA) is the regulator of the capital markets in Rwanda with very explicit responsibilities stipulated in the Capital Market Act of 2011. The CMA was initially established by an Order in 2007 to guide the development of capital markets in Rwanda, facilitate the trading of debt and equity securities and regulate the RSE. However, it would appear there are no explicit provisions on the oversight of CSDs by the CMA. Article 9 of the law governing the holding of securities provides for the Central Bank to conclude memorandum of understanding with the Capital Market Authority in carrying out its oversight responsibility. The CMA supervises and regulates stockbrokers primarily before they become CSD participants in line with the requirements of the BNR regulations. A memorandum of understanding (MoU) between the BNR and the CMA is in existence. The MoU forms part of the governance framework/structure that facilitates the collaboration between the two regulators. BNR also collaborates with the RSE in sharing knowledge, expertise and reviewing regulations relevant to capital markets.

\section{G. Tanzania: efficiencies through links}

Tanzania represents Model D, with the special feature of realizing efficiencies through a link between the two CSDs for the settlement of government securities.

There are two CSDs in Tanzania. In line with its fiscal agent responsibilities, the Bank of Tanzania (BOT) owns and operates the CSD for government securities. The Government Securities System (GSS) was established under the Loans, Grants and Guarantees Act 1974, and has its own book entry regulations. The National Payment System Act gives the BOT an 
explicit mandate to provide settlement services. The GSS is the CSD for all issued Treasury bills and bonds. The BOT also owns and operates the Tanzania Interbank Settlement System (TISS), the real time gross settlement system, which was implemented in 2004, and processes interbank payments and net obligations arising from the automated clearing houses and card switches. The GSS is linked to the TISS to facilitate delivery-versus-payment in the settlement of securities transactions.

The Dar es Salaam Stock Exchange (DSE) operates the CSD for equities and corporate bonds. In addition, it keeps a copy of the Treasury bonds register. The DSE, a not for profit entity, was established in 1994 under the Capital Markets and Securities Act and became operational in 1998. In 2015 it demutualized, self-listed and commenced selling shares in 2016. A new Capital Markets Act is under consideration, which will provide the Capital Markets and Securities Authority (CMSA) with an explicit mandate to license, regulate and supervise CSDs. The DSE is in the process of establishing the CSD as an independent, wholly owned subsidiary, which will be licensed by the CMSA.

Efficiencies are realized through a link between the two CSDs to improve the settlement efficiency for government securities; further efficiencies are being sought through automatization of this link. In 2002, the DSE started to offer trading of Treasury bonds on its platforms, providing a broad range of investors access to these securities. A link was created between the DSE and the BOT to facilitate settlement of trades in government securities conducted in the DSE, which are held GSS. Plans are underway to further improve efficiencies by electronically linking the DSE CSD and the GSS. The electronic link will replace the current manual procedures, thereby improving Treasury bond settlement in terms of time, cost and accuracy. For example, settlement can take place earlier $(\mathrm{T}+1$ could be achieved and $\mathrm{T}+0$ settlement would be possible, if requested). This is expected to improve the liquidity of Treasury bonds and increase activity in the securities market.

Also, efficiencies are being pursued at a regional level. The East African Community (EAC) member countries agreed to link stock exchanges' CSDs through a hub and spoke regional CSD in Arusha (Tanzania). These EAC links offer an opportunity for cross border trading and settlement of securities between the member countries. However, the costs to set up and operate the processes and systems can be high for low volume transactions. Also, a legal and regulatory framework would need to be developed. 


\section{References}

Asian Development Bank, 2014. Basic Principles on Establishing a Regional Settlement Intermediary and Next Steps Forward, Cross-border Settlement Infrastructure Forum.

Bossone, B., and J.-K. Lee (2004), “In Finance, Size Matters,” IMF Staff Papers, Volume 51, Number 1

Cirasino, M., Garcia, J., Guadamillas, M., Montes-Negret, F., 2007. Reforming Payments and Securities Settlement Systems in Latin America and the Caribbean.

Committee on Payments and Market Infrastructures (CPMI), 2017. Distributed Ledger Technology in Payment, Clearing and Settlement: An Analytical Framework. Basel.

Committee on Payment and Settlement Systems (CPSS) 2005, Central Bank Oversight of Payment and Settlement Systems

CPSS publication, 2006, General Guidance for National Payment System Development.

CPSS-IOSCO, 2001, Recommendations for Securities Settlement Systems.

CPSS-IOSCO, 2012. Principles for Financial Market Infrastructures.

European Union, 2009. Clearing and Settlement in the EU, Policy Department Economic and Scientific Policy, IP/A/ECON/EC/2009-001.

Giovannini Group, 2002. Cross-border clearing and settlement arrangements in the European Union, Report by the Giovannini Group, "Economic Paper”, No. 163.

Giovannini Group, 2003. The Giovannini Group Second Report on EU Clearing and Settlement Arrangements. Brussels.

Guadamillas, M. and Keppler, R., 2001. Securities Clearance and Settlement Systems, a guide to best practices.

He, Dong, Ross B Leckow, Vikram Haksar, Tommaso Mancini Griffoli, Nigel Jenkinson, Mikari Kashima, Tanai Khiaonarong, Celine Rochon, Hervé Tourpe, 2017. Fintech and Financial Services: Initial Considerations, IMF Staff Discussion Note No. 17/05.

International Monetary Fund and World Bank, 2001. Developing Government Bond Markets; A Handbook.

Kazarian, E., 2006. Integration of the Securities Market Infrastructure in the European Union: Policy and regulatory issues, IMF Working Paper.

Mercier, F. and Sauer, S., 2013. Optimal central securities depository reshaping toward TARGET2-Securities, Journal of Financial Market Infrastructure 2(2), 3-51.

Russo D., Hart, Malaguti M. and Papathanassiou C., 2004. Governance of securities clearing and settlement systems, ECB Occasional paper series. 
Schmiedel H., Malkamäki, M., Tarkka, J., 2004. Economies of scale and technological development in securities depository and settlement systems. Chapter 6 of Performance of international securities markets. Bank of Finland.

Van Cayseele, P., Wuyts, C., 2007. Cost efficiency in the European securities settlement and depository industry. Journal of Banking \& Finance, Volume 31, Issue 10.

World Bank, 2014. Guidelines for the successful regional integration of financial infrastructures, Financial Infrastructure Series.

World Bank, 2017; 'Payment Systems Worldwide - A Snapshot, Outcomes of the Global Payment Systems Survey 2015’, Financial Infrastructure Series, forthcoming. 


\section{Annex 1. Global Map of Central Securities Depositories}

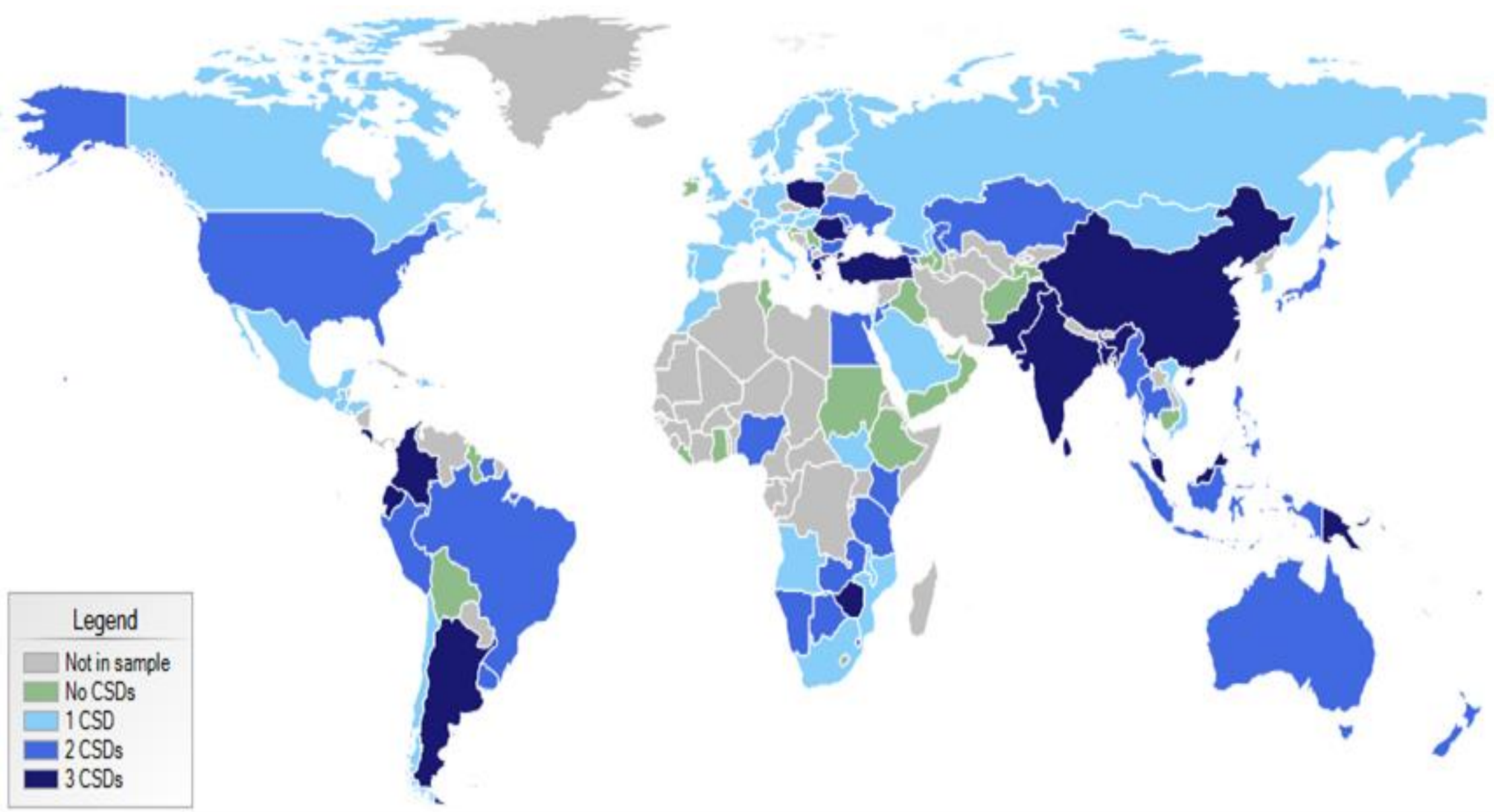




\section{Annex 2. Decision Tree Combining Safety and Efficiency Considerations}

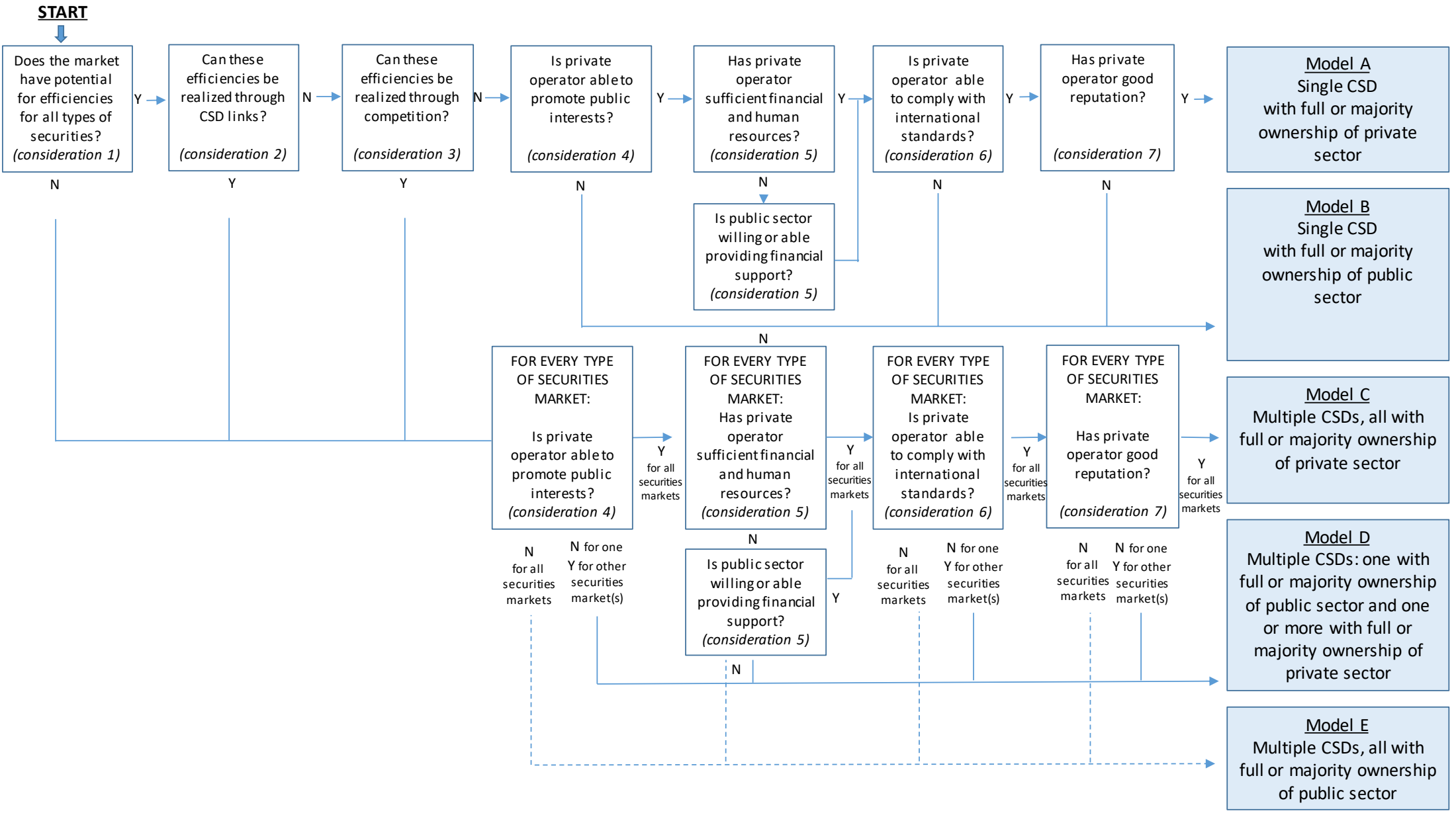

